\title{
XII ème CONGRES DE LA SALF \\ TOURS, 8-9 décembre 1995
}

\section{Résumés des communications affichées}

\section{SPERMIOLOGIE - SPERMATOGENESE}

63 ABP testiculaire et fertilité chez l'homme

A.GERARD, A.CHESNEL, C.BUBESSY, J.HUBERT, M.PARACHE, V.SCHOUMACKER, H.GERARD

63 Analyse immunohistochimique des constituants de la barrière hématotesticulaire : étude préliminaire sur microbiopsies testiculaires.

J.Y.SCOAZEC, A.DEVAUX, G.TRITTO, E.ERDEI, G.ARVIS, G.FELDMANN

65 Développement d'une méthode de quantification des ARN Messagers par RT-PCR dans les biopsies testiculaires.

H.LEJEUNE, R.LEVY, C.BREBANT, J.C. CRAVE, N.BERGER-DUTRIEUX, M.DEVONEC, P.DURAND, J.M.SAEZ, M.PUGEAT

66 Présence de cytochrome $\mathrm{P} 450$ aromatase dans les cellules germinales du rat mature. J.LEVALLET, H.MITTRE, G.E.SERALINI, P.LEYMARIE, S.CARREAU

67 Effet trophique positif de l'inhibine-A et de l'activine-A recombinantes humaines sur les cellules de Leydig de porc immature in vitro.

H.LEJEUNE, F.CHUZEL, P.SANCHEZ, J.P.MATHER, P.DURAND, J.SAEZ

68 Infertilité masculine et cytopathie mitochondriale.

M.F.CHRETIEN, V.RHOMER, I.PENISSON-BESNIERI, F.GRIZON, P.LESTIENNE

69 Déclin de la spermatogenèse : l'hypothèse "éthers de glycol".

A.CICOLETTA

70 Conduite à tenir devant une nécrozoospermie.

C.BARTHELEMY, L.N DUNAYO, S.HAMAMAN, M.J.THARANNE, P.LECOMTE

72 Substitution du jaune d'oeuf par des liposomes dans le milieu cryoprotecteur : effets sur la fonction cinétique et le pouvoir fécondant des spermatozoïdes humains B.SION, V.CHEVALIER, G.GRIZARD, D.BOUCHER

73 L'hypotaurine et la taurine dans le spermatozoïde et les sécrétions génitales P.GUERIN

74 Synthèse d'hypotaurine et de taurine par les spermatozoïdes et les cellules tubaires P.GUERIN

75 Métabolisme énergétique du sperme humain pendant la Capacitation : étude par spectroscopie de résonance magnétique du $31 \mathrm{P}$

S.HAMAMAH, F.SEGUIN, D.ROYERE, C.BARTHELEMY, S.AKOKA, F.PERROTIN, J.LANSAC.

76 Implication de l'anion superoxyde dans la réaction acrosomique des spermatozoïdes humains induite par un calcium ionophore

J.F.GRIVEAU, P.RENARD, D.LE LANNOU 
77 Anomalies de la tructure chromatinienne des spermatozoïdes humains détectées par la cytométrie de flux à l'acridine orange.

Y.SOFFER, R.GOLAN, L.SHOCHAT, R.WEISSENBERG, L.M.LEWIN

78 Identification des stades précoces de la spermatogenèse dans des éjaculats d'hommes hypofertiles par l'utilisation d'un anticorps monoclonal anti-proacrosine.

B.SOULEZ, P.VOLLE, M. LEROY-BILLIARD, E.HERMAND, A.DEFOSSEZ

78 Marquage des spermatozoïdes humains avec deux Fluorochromes : application au test d'attachement des spermatozoïdes à la zone pellucide d'ovocytes humains non fécondés.

R.LEVY, C.Clavel, F.EuSTaChe, M.BenChaib, J.LoRNaGe, M.C.PINATEL, H.CoRdoNNIER, J.F.GUERIN

79 Mise en évidence et localisation de récepteurs aux cytokines à la surface des spermatozoïdes humains.

P.SCHWED, R.FIERRO, B.GOBERT, B.FOLIGUET, M.C.BENE, G.FAURE

80 Antigènes de membrane définis par les anticorps anti-spermatozoïdes de classe IgA et IgG

J.AUER, M.DE ALMEIDA, P.JOUANNET

81 Incidence de la présence d'autoanticorps chez l'homme sur la fertilité du couple : étude rétrospective du CHU de Caen

E.SZERMAN-JOLY, N.DEFENDUILLERE, D.HERLICOVIEZ, I.DENIS, A.SAUVALLE, M.HERLICOVIER, M.A.DROSDOWSKY

82 Analyse automatisée du mouvement des spermatozoïdes : Reproductibilité et intérêt pour le choix d'une technique d'AMP.

C.FILLION, M.KRAEMER, B.MARTIN-PONT, J.GONZALES

83 Analyse du plasma séminal humain en spectroscopie à résonance magnétique, en relation au temps d'incubation.

M.EUGENE, L.LE MOYEC, E.ERDEI, V.MALETIC, J.TRITTO, G.ARVIS, A. LE DUC

84 L'assurance de la qualité en biologie de la reproduction : application au spermocytogramme

A.BOURGUIGNAT, A.CLAVERT, G.FERARD

85 Troubles de la fertilité masculine associés à un remaniement chromosomique complexe : à propos d'un cas d'azoospermie avec translocation $\mathrm{t}(7 ; 8 ; \mathrm{y})$

S.BRIAULT, A.GUICHET, C.BARTHELEMY,CL.MORAINE

85 Cryptorchidie et infertilité masculine

R.MIEUSSET, L.BUJAN, G.MANSAT, A.MANSAT, F.PONTONNIER,

\section{EPIDIDYME}

87 Caractérisation et identification de protéines synthétisées par l'épididyme de porc P.SYNTIN, J.L.DACHEUX, F.DACHEUX

87 Polarisation des sécrétions protéiques dans l'épididyme de porc : analyse quantitative P.SYNTIN, J.L.DACHEUX, F.DACHEUX 
88 Analyse quantitative et qualitative de l'épididyme dans les azoospermies excrétoires : approche morphométrique par analyse d'image.

F.PERROTIN, S.HAMAMAH, D.ROYERE, C.BARTHELEMY, G.BODY, J.LANSAC

89 L'absence d'une protéine épididymaire du spermatozoïde est associée à certains cas d'infertilité idiopathique chez l'homme.

F.BOUE, R.SULLIVAN

\section{ASSISTANCE MEDICALE A LA PROCREATION}

90 Evaluation d'un protocole simplifié pour l'injection intracytoplasmique d'un spermatozoïde (ICSI)

M.JEAN, P.BARRIERE, S.MIRALLIE, H.LUCAS, M-F.DUBIN, M.ROCH

91 FIV ou ICSI ? Valeur prédictive des différents paramètres du sperme.

C.WITTEMER, S.WARTER, B.SUDAN, R.M.DEMAND, J.OHL, K.BETTAHAR-LEBUGLE, L.MOREAU, P.DELLENBACH, Y.RUMPLER.

92 Etude de facteurs prédictifs d'échecs répétés de fécondation in vitro. H.LEJEUNE, C.ERIBON, D.BOULIEU, V.BIED, F.PAYAN, M.PUGEAT, J.C.CZYBA, J.F.GUERIN

93 FIV et infertilité masculine ; optimisation du taux de grossesse après modification de la technique de capacitation du sperme : étude prospective sur 79 cas

C.WITTEMER, J.OHL, K.BETTAHAR-LEBUGLE, L.MOREAU, P.DELLENBACH

\section{SEXUALITE}

94 Quels dosages hormonaux dans les dysfonctions érectiles?

J.BUVAT, A.LEMAIRE, M.BUVAT-HERBAUT, J.RATAJCZYK, G.COUPLET, J.C.FOURLINNIE

96 Evaluation du contexte hormonal chez des patients présentant des troubles respiratoires durant le sommeil (hypopnées ou syndrome des apnées du sommeil) A.LEMAIRE, J.BUVAT

97 Résultats à 2 ans d'une étude multicentrique européenne sur la sécurité et l'efficacité du traitement par auto-injections intracaverneuses de prostaglandine $\mathrm{E}_{1}\left(\mathrm{PGE}_{1}\right)$ chez les patients avec dysfonction érectile chronique.

J.Buvat, D.HaURI, D.S.KROTOVSKY, E.MEULEMAN, V.MiChal, H.Porst, G.WAGNER, E.WESPES

98 Chirurgie pénienne d'agrandissement : traitement chirurgical ou "pénis building"? Techniques, indications, limites, contre-indications.

M.SCHOUMAN, M.ABECASSIS, J.MIGNOT

\section{DIVERS}

100 Apport de l'exploration biologique clinique et radiologique aux O.A.T.S. associés à une infection spermatique et / ou une leucospermie.

N.RIVES, L.SIBERT, B.MACE

101 Hypospermie, kyste prostatique et infertilité. A propos de 4 Cas.

J.M.RIGOT, B.HATTAB, L.LEMAITRE, E.MAZEMAN

101 Agénésies vésiculo-diférentielles et gène C.F.T.R.

F.PIGEON, D.GAILLARD, C.CLAVEL, C.FEREC, B.DELEPINE, M.C.MELIN, G.HARIKA,

Y.YOUINOU, P.VILLENA, B.LARDENNOIS, C.QUEREUX. 


\section{SPERMIOLOGIE SPERMATOGENESE}

\section{ABP TESTICULAIRE ET FERTILITE CHEZ L'HOMME}

A. Gerard 1, A. Chesnel 2, C. Dubessy 2, J. Hubert 3, M. Parache 4,

V. SCHOUMACKer 4, H. GERARDL

1. Laboratoire d'Histologie-Embryologie II,

Faculté de médecine de Nancy.

2. Laboratoire de Biologie expérimentale, Faculté des Sciences de Nancy

3. Service d'Urologie, CHRU. Nancy-Brabois

4. Laboratoire d'Anatomie pathologique du

centre anticancéreux de Nancy-Brabois.

\section{Introduction - But}

L'androgen-binding protein de rat, produite par les cellules de Sertoli et l'androgen-binding protein de l'homme présentent des homologies de séquence importantes $(78 \%)$. Chez les rongeurs, l'ABP est considérée depuis longtemps comme un excellent marqueur de la fonction Sertolienne et son rôle dans le contrôle de la spermatogenèse (présence de récepteurs sur la lignée germinale) et de la fertilité est devenu évident.

Dans le but de vérifier si l'ABP pourrait également servir de marqueur de la fertilité chez l'homme, nous avons commencé à étudier son expression soit par immunocytochimie, soit par Northern Blotting sur des biopsies testiculaires provenant de patients examinés pour bilan de stérilité d'origine variée.

\section{Étude immunocytochimique:}

Les fragments biopsiques ont été fixés dans le liquide de BouinHollande puis inclus dans la paraffine. Les coupes ont été traitées soit avec un sérum de lapin anti-ABP testiculaire de rat préparé par J. Closset, soit avec un anticorps monoclonal anti-SBP humaine préparé par $\mathrm{C}$. Grenot. La réaction immunocytochimique a été révélée par la réaction avidine-biotine-peroxydase selon le kit LSAB de Dako.

\section{Étude par Northern Blotting:}

Des ARN totaux ont été extraits à partir des fragments biopsiques selon la technique de Chomczynski. Des transcripts d'ABP et de SBP ont été recherchés par hybridation avec la sonde ADNc de l'ABP de rat (fournie par J Reventos) et la sonde de la SBP humaine (fournie par G.E. Seralini) marqués à l' 32PdCTP.

\section{Résultats}

Jusqu'à présent, les biopsies correspondant à des troubles de la fertilité par insuffisance sécrétoire testiculaire sont associés à un déficit marqué de l'expression de l'ABP/SBP.

A l'inverse, les oligospermies ou azoospermies excrétoires se caractérisent par une expression conservée de l'ABP au niveau testiculaire. La quantité d'ARN extrait à partir d'une biopsie testiculaire est suffisante pour détecter les ARNm d'ABP/SBP.

Afin de préciser l'aide au diagnostic que peut apporter cette approche, la même étude est en cours sur des biopsies testiculaires provenant de séminomes et de cancer in situ.

\section{ANALYSE IMMUNOHISTOCHIMIQUE DES CONSTITUANTS DE LA BARRIE- RE HEMATOTESTICULAIRE: ETUDE PRELIMINAIRE SUR MICROBIOP. SIES TESTICULAIRES}

\author{
JY. SCOAZEC*, A DEVAUX*, G. TRITTO**, E. \\ ERDEI**, G. ARVIS**, G. FELDMANN* \\ *Service d'Histologie-Embryologie-Cytogene- \\ tique-Biologie Cellulaire, Hopital Bichat, et \\ **Service d'Urologie-Andrologie, Hopital Tenon, \\ Paris
}

Des travaux récents ont souligné l'intérêt diagnostique et/ou pronostique de la biopsie testiculaire dans diverses situations 
cliniques, dont la varicocèle, l'azoospermie et les hypogonadismes hypogonadotropes. Jusqu'à présent, l'analyse de la biopsie testiculaire repose sur l'examen histologique, éventuellement complété par une étude morphométrique permettant une évaluation semi-quantitative de certains paramètres morphologiques. Le but de notre travail a été d'évaluer la faisabilité des techniques imunohistochimiques sur microbiopsies testiculaires et d'apprécier l'intérêt de marqueurs immunohistochimiques pour l'analyse qualitative détaillée de la barrière hématotesticulaire.

\section{Matériel et méthodes}

Le groupe d'étude comprenait 7 patients, chez lesquels des microbiopsies ont été réalisées dans au moins deux quadrants testiculaires. Les indications de la biopsie étaient: varicocèle (4 cas), azoospermie ( 2 cas), syndrome de Klinefelter (I cas). Les prélèvements ont été immédiatement congelés dans l'azote liquide et conservés à $-80^{\circ} \mathrm{C}$ jusqu'à leur analyse. Une technique d'immunoperoxydase indirecte a été appliquée à des coupes au cryostat de $6 \mathrm{~mm}$, séchées à l'air libre et fixées à l'acétone. Les marqueurs suivants ont été testés: (a) marqueurs de cellules épitheliales (protéines d'adhésion intercellulaire: $\mathrm{E}$ - et $\mathrm{N}$ cadherines, protéines d'adhésion à la matrice extracellulaire: integrines), (b) constituants de la matrice extracellulaire (collagènes I, III, IV et VII, laminine, fibronectine, vitronectine, tenascine, unduline), (c) marqueurs de cellules stromales (protéine CD34), (d) marqueurs de cellules endothéliales (protéine PECAM-I), (e) marqueurs de cellules endocrines (protéine NCAM).

\section{Résultats}

Des résultats interprétables ont été obtenus dans tous les cas. Chaque prélèvement biopsique comportait de 8 a 21 tubes séminifêres. Les principaux caractères phénoty- piques suivants ont été observés, indépendamment de la pathologie sousjacente. Les cellules de Sertoli exprimaient la N-cadherine, mais, à la différence des autres cellules épithéliales, n'exprimaient pas la Ecadherine. Leur répertoire d'intégrines était restreint aux molécules a6b1 et a6b4, des récepteurs de la laminine. La membrane basale des tubes séminifères, comme les autres basales épithéliales, comportait les constituants suivants: collagènes IV et VII, laminine, fibronectine et était dépourvue de tenascine; son caractère particulier était sa richesse en vitronectine, habituellement considérée comme caractéristique des basales vasculaires. Les cellules stromales étaient facilement identifiées par l'anticorps anti-CD34, sous la forme d'une couche de cellules allongées entourant la basale des tubes séminiferes. Les cellules endothéliales étaient réactives avec l'anticorps antiPECAM-l, utilisable pour une étude détaillée de la microcirculation testiculaire. Les cellules de Leydig étaient révélées par l'anticorps anti-NCAM sous forme de cellules isolées ou d'amas dispersés dans le tissu interstitiel.

\section{Conclusion}

Notre étude préliminaire démontré la faisabilité de l'étude immunohistochimique des microbiopsies testiculaires. L'utilisation d'une gamme de marqueurs spécifiques des différents constituants de la barrière hématotesticulaire, en complément de l'étude histologique conventionnelle, permet une caractérisation détaillée du microenvironnement des cellules germinales et fournit les bases d'une évaluation qualitative précise de ses modifications en pathologie. 


\section{DEVELOPPEMENT D'UNE METHODE DE QUANTIFICATION DES ARN MES- SAGERS PAR RT-PCR DANS LES BIOPSIES TESTICULAIRES.}

Lejeune $\mathrm{H}^{*} \mathrm{~F}$, Levy $\mathrm{R}^{*}$, Brebant $\mathrm{C}^{*}$, Crave JC*, Berger-Dutrieux $\mathrm{N}^{* * *}$, DevoneC $\mathbf{M}^{* * * *}$, Durand PF:, SaEz JMF, Pugeat $\mathbf{M}^{*}$.

* Laboratoire de la Clinique Endocrinologique, *** Laboratoire d'anatomopathologie, ****Service d'Urologie, Hôpital de l'Antiquaille \& FIN-

SERM-INRA U418, Hôpital Debrousse, Lyon.

La physiopathologie des troubles de la spermatogenèse reste très mal connue. Afin de mieux comprendre l'implication des facteurs paracrines de régulation de la spermatogenèse en pathologie humaine, nous avons développé une méthode de mesure des ARN messagers par reverse transcription - polymerase chain réaction (RT-PCR), applicable à des fragments testiculaires de petite taille, tels que ceux obtenus lors des biopsies testiculaires. Nous présentons ici les aspects méthodologiques développés pour répondre aux contraintes liées :

1) à la taille réduite des échantillons,

2) au caractère non renouvelable de la biopsie testiculaire chirurgicale,

3) au fait que la pathologie étudiée induit une modification de la composition cellulaire des échantillons (raréfaction des cellules de la lignée germinale).

Les développements méthodologiques ont été effectues à partir des testicules prélevés chez un sujet de 23 ans en état de mort cérébrale (histologie normale) et de 3 testicules pathologiques obtenus lors de castration pour cancer de la prostate :

1) hypospermatogénèse avec production de spermatozoïdes dans moins de $10 \%$ des tubes,

2) atrophie parenchymateuse majeure avec fibrohyalinose et involution sertolienne des tubes séminifères,
3) involution hyaline des tubes séminifere avec hyperplasie leydigienne. Nous avons mesuré l'expression de gènes marqueurs de divers types cellulaires, clusterine pour les cellules de Sertoli, cytochrome P450 side chain cleavage ( $\mathrm{CyP} 450 \mathrm{scc}$ ) pour les cellules de Leydig, protamine 1 pour les cellules germinales post meiotiques; et d'un facteur para/autocrine testiculaire, la sous unité de l'inhibine, par rapport au gène de référence classiquement utilisé, la b-actine. Les choix méthodologiques ont été les suivants: extraction des ARN totaux par broyage au polytron, RT amorcées par oljgodT, amorces de PCR de composition similaire (20-mer, 45$55 \%$ CG), situées sur des exons différents, coamplification du cDNA d'intérêt et du cDNA de référence dans le même tube, amplification décalée pour corriger les différences d'expression entre gène d'intérêt et gène de référence, révélation des produits de PCR par Southern blot-hybridation par sondes marquées au 32P-CTP - autoradiographie, mesure par densitométrie pendant la phase exponentielle d'amplification. Ces méthodes permettent d'obtenir une mesure relative d'un ARNm d'intérêt par rapport à un $\mathrm{ARNm}$ de référence à partir de $0,1 \mathrm{mg}$ d'ARN total (au lieu de 10-40 mg en Northern Blot).

La mesure des ARNm de l'inhibine dans des ARN testiculaires dilués par des ARN d'une lignée cellulaire n'exprimant pas l'inhibine (HepG2) montre une bonne corrélation avec les valeurs attendues $(r=0,989$; $p=0,0015$ ) et une bonne corrélation entre RT-PCR et Northern Blot $(r=0,995$; $\mathrm{p}=0,000 \mathrm{~S}$ ). En comparant l'expression des gènes étudiés dans les échantillons pathologiques par rapport au sujet contrôle, on observe une bonne corrélation entre RTPCR et Northern blot $(r=0,914 ; p=0,0002)$ et entre RT-PCR réalisées sur des fragments biopsiques (1-5 $\mathrm{mg}$ ) et des fragments de taille plus importante $(\sim 100 \mathrm{mg})(\mathrm{r}=0,931$; $\mathrm{p}=0,0003$ ). Nos résultats concordent avec les constatations histologiques: absence d'expression de la protamine 1 dans les 
troubles sévères de la spermatogenèse, augmentation de l'expression du CyP450scc en cas d'hyperplasie leydigienne. L'expression de l'inhibine est en relation avec la proportion de cellules somatiques dans les échantillons. Ceci indique la nécessite, dans les troubles de la spermatogenèse, d'une mesure relative de l'expression des facteurs paracrines, par rapport à des marqueurs spécifiques de chaque type cellulaire du testicule.

Ces méthodes vont permettre des études de l'expression des gènes des facteurs régulateurs de la spermatogenèse sur les biopsies testiculaires réalisées lors des soins de l'infertilité des patients.

Ce travail est financé par le Réseau de Recherche Clinique INSERM $n^{\circ} 493010$, la Commission Recherche des Hospices Civils de Lyon et le Ministère de la Santé (Projet National de Recherche Clinique).

\section{PRESENCE DE CYTOCHROME P450 AROMATASE DANS LES CELLULES GERMINALES du RAT MATURE.}

\section{J. Levallet, H.Mittre, G. E. Seralini, P.LEYMARIE ET S.CARREAU. \\ CNRS EP 009, Biochimie-IRBA,Université de Caen, France}

Dans les cellules somatiques testiculaires de rat, l'activité aromatase évolue avec l'âge sous l'influence des gonadotrophines, glissant d'une dominance sertolienne à une dominance leydigienne (Papadopoulos,1986). Chez l'adulte, ces deux compartiments interagissent via des facteurs paracrines responsables notamment d'une régulation plus fine de l'activité aromatase leydigienne (Carreau, 1994). En outre, les travaux de Nitta (1993) montrent une synthèse d'oestrogènes plus élevée dans les cellules germinales que dans les cellules de Leydig chez la souris adulte.
$\mathrm{Au}$ vue de ces données, notre objectif a donc été de rechercher le (ou les) $\mathrm{ARNm}$ de la cytochrome $\mathrm{P} 450$ aromatase (P450 arom) dans les différentes populations cellulaires testiculaires du rat. Le nombre de copies de l'ARNm de l'aromatase se révélant trop faible dans le testicule entier, nous avons donc utilisé la technique de PCR couplée à une étape de transcription inverse (RTPCR) permettant d'amplifier à partir d'ARN total une portion d'ADN complémentaire codant pour la cytochrome P450 arom grâce à deux amorces spécifiques correspondant à une séquence de 23 mer (exon 8) pour l'une et de 24 mer (exon 9) dans la région du site actif pour l'autre. Celles-ci permettent l'amplification d'un fragment de 289 nucléotides contenant la région codant pour l'hélice 1. Des cellules de Leydig, de Sertoli ainsi que des cellules germinales (spermatocytes pachytènes, spermatides rondes et spermatozoïdes) ont été purifiées. Après un choc thermique de $10^{\prime}$ à $94^{\circ} \mathrm{C}$ sur 2000 cellules, l'étape de transcription inverse est menée durant $60^{\prime}$ à $37^{\circ} \mathrm{C}$ avec $200 \mathrm{U}$ de M-MLV RT. La PCR se fait en 35 cycles $\left(1^{\prime}\right.$ à $94^{\circ} \mathrm{C}, 1^{\prime}$ à $58^{\circ} \mathrm{C}$ et $2^{\prime}$ à $72^{\circ} \mathrm{C}$ ) en présence de 40 nmoles de dNTP, 50 pmoles d'amorces et 1,5 U de Taq Polymerase. La séquence amplifiée est visualisée par le bromure d'éthidium sur gel d'agarose $2 \%$. Pour chaque type cellulaire présentant un signal, le fragment est transformé en $\mathrm{ADN}$ simple brin et séquence par la méthode de Sanger. Dans le testicule de rat mature, un fragment est détecté après RT-PCR dans les cellules somatiques testiculaires, mais également dans les spermatocytes pachytènes, les spermatides rondes et les spermatozoïdes testiculaires. Ce fragment possède $100 \%$ d'homologie avec la séquence de l'aromatase d'ovaire de rat et ce pour tous les types cellulaires précités.

Ces résultats mettent en évidence l'expression pluricellulaire du gène de l'aromatase dans le testicule de rat et confirment la possibilité d'une synthèse d'oestradiol dans les cellules germinales du mâle. 


\section{EFFET TROPHIQUE POSITIF DE L'INHIBINE-A ET DE L'ACTIVINE-A RECOMBINANTES HUMAINES SUR LES CELLULES DE LEYDIG DE PORC IMMATURE IN VITRO.}

\author{
H . Lejeune, F. Chuzel, P. Sanchez, JP. \\ MATHER*, P. DURAND, JM. SAEZ
}

INSERM-INRA U.418, Hopital Debrousse, Lyon, France et ${ }^{*}$ Genentech, San Francisco, CA, USA.

L'inhibine et l'activine sont des protéines bioactives de structure apparentée, appartenant à la famille des TGF- $\beta$ s, initialement isolées à partir des gonades et caractérisées par leur effet opposé, inhibiteur pour l'inhibine et stimulant pour l'activine, sur la sécrétion de FSH par les cellules gonadotropes hypophysaires. Les études réalisées ces dernières années ont montré que ces protéines n'étaient pas seulement impliquées dans le rétrocontrôle de la sécrétion de FSH mais avaient des effets locaux intragonadiques ainsi que des sites de production et des effets extra-gonadiques. Les premiers résultats, établis avec des préparations extractives, montrant un effet stimulant de l'inhibine et un effet inhibiteur de l'activine sur les fonctions des cellules de Leydig de rat [1], n'ont pas été confirmés par l'ensemble des auteurs.

Nous avons étudié l'effet de l'inhibine-A $(\beta A)$ recombinante humaine et de l'activineA ( $\beta A-\beta A)$ recombinante humaine (Genentech, San Francisco, USA), sur les cellules de Leydig de porc immature in vitro. Les cellules de Leydig ont été préparées par digestion par la collagénase de testicules de porc de 3 semaines, purifiées sur gradient de Percoll et cultivées en milieu chimiquement défini. Les cellules ont été traitées par des doses croissantes d'inhibine-A ou d'activineA $(0,5-200 \mathrm{ng} / \mathrm{ml})$. Le traitement aigu par l'inhibine-A ou l'activine-A ne stimule pas directement la production de testostérone. Par contre, le traitement chronique des cellules de Leydig pendant 48 heures, aussi bien par l'inhibine-A que par l'activine-A stimule de manière dose dependante la production de testostérone stimulée pendant 2 heures par une dose maximale (109M) d'hCG, avec un effet maximum de $2,8+/-0,5$ fois pour l'inhibine-A et $2,4+/-0,6$ fois pour l'activine-A. Cet effet est associé à une augmentation des récepteurs à la LH/hCG (mesures par liaison de 1'l25IhCG) et de leurs ARN messagers $(2,7+/-0,4$ et $2,8+/-0,9$ fois pour l'inhibine-A et l'activine-A respectivement). L'inhibine-A et l'activine-A augmentent de manière dose dépendante les ARNm du cytochrome P450 17 hydroxylase $(6,8+/-1$ et $3,7+/-0,8$ fois respectivement), mais n'ont pas d'effet sur les ARNm des cytochromes P450scc et P450aromatase. Les ARNm de la $3 \beta$ hydroxysteroide-dehydrogenase ne sont augmentés que par l'activine-A $(1,4+/-0,1$ fois), l'inhibine-A n'a pas d'effet propre mais inhibe l'effet stimulant de l'activine lorsque les cellules sont traitées par les 2 protéines en même temps. En accord avec les modifications des ARNm des enzymes de la stéroïdogénèse, l'inhibine et l'activine augmentent la conversion de 22R-OH-cholesterol, de progestérone et de DHEA exogènes en testostérone.

En conclusion, nos résultats démontrent que l'inhibine-A et l'activine-A ont toutes deux un effet stimulant sur les fonctions différenciées spécifiques des cellules de Leydig de porc immature invitro. Bien qu'il puisse exister des différences interespèces, nos résultats sont en faveur d'un rôle de l'inhibine et de l'activine comme facteurs paracrines (et/ou autocrines) intratesticulaires. Les effets locaux de l'inhibine et de l'activine dans le testicule apparaissent multiples, agissant d'une part sur les cellules germinales $[2,3]$ et d'autre part sur l'état de différenciation des cellules de Leydig, c'est à dire leur aptitude à produire de la testostérone sous l'influence de la LH. 


\section{REFERENCES}

1. Hsueh AJW, Dahl .KD, Vaughan J, Tucker E, Rivier J, Bardin CW, Vale W. Heterodimers and homodimers of inhibin subunits have different paracrine action in the modulation of luteinizing hormone-stimulated androgen biosynthesis. Proc Natl Acad Sci USA, 1987;84:5082-5086.

2 - Mather JP, Attie KM, Woodruff TK, Rice GC, Phillips DM. Activin stimulates spermatogonial proligeration in germ-Sertoli cell cocultures from immature rat testis. Endocrinology. 1990;127:3206-3214.

3 - Hakovirta H, Kaipia A, Soder 0, Parvinen M. Effects of activin-A, inhibin-A and transforming growth factor-l l on stage-specific deoxyribonucleic acid synthesis during rat seminiferous epithelial cycle. Endocrillology 1993; 133 :1664-1668.

Ce travail est financé par le Reseau de Recherche Clinique INSERM $n^{\circ} 493010$.

\section{INFERTILITE MACULINE ET CYTOPATHIE MITOCHONDRIALE}

MF. ChrÉtien *, V. RoHMeR**, I. PenissonBESNIERI***, F. GRIZON .****., P. LESTIENNE******

*Laboratoire d'Histologie Embryologie Cytologie, CHU Angers. ${ }^{* *}$ Service de

Médecine C, CHU Angers. ***Service de Neurologie A, CHU Angers. ${ }^{* * * *}$ Service Commun de Microscopie Electronique, Faculté de Médecine, Angers. ******INSERM. U 298, CHU Angers CEDEX 01

\section{Objet}

Infertilité masculine avec oligospermie sévère chez un patient présentant un ptosis. L'examen histologique de la biopsie musculaire a mis en évidence des anomalies morphologiques caractéristiques d'une cytopathie mitochondriale. Des anomalies structurales de l'ADN mitochondrial ont été observées dans le muscle et les spermatozoïdes.

Patient : Homme de 33 ans vivant en couple depuis 2 ans, sans antécédent personnel et familial.

\section{Données des examens clinique et com- plémentaires}

Endocrinologique : L'examen clinique est normal sur le plan endocrinien. Les taux de $\mathrm{LH}$ et Testostérone plasmatique sont normaux. Seule la FSH est élevée à $20 \mathrm{UI} / \mathrm{L}$ $(\mathrm{N}<9)$. Le reste du bilan est normal et l'hypothèse d'un adénome gonadotrope a été éliminée.

Neurologique : Ptosis bilatéral asymétrique, d'aggravation progressive depuis une vingtaine d'années, sans limitation des mouvements oculaires ni signe clinique d'atteinte de la musculature extra-oculaire. Aréfléxie ostéo-tendineuse des membres inférieurs. A l'examen électrophysiologique, on note une abolition des potentiels sensitifs des nerfs saphènes externes. Enfin l'examen histologique du deltoïde permet de mettre en évidence une dizaine de Ragged Red Fibers et des fibres cytochrome $\mathrm{C}$ oxydase négative.

Cytologique : 5 spermogrammes ont été pratiqués en 2 ans : 2,3 millions de spz en moyenne par $\mathrm{ml}$, avec une mobilité, à la première heure, inférieure à $5 \%$. L'examen en microscopie électronique n'a pu, faute de spz en assez grande quantité, mettre en évidence d'anomalies mitochondriales.

Biologique : L'analyse par Southern blot de l'ADN mitochondrial des biopsies musculaires et des spz du patient comparés à des spz témoins indique la présence de délétions multiples en faible quantité. Des études complémentaires par PCR permettront de vérifier ces anomalies.

\section{Conclusion}

Une cytopathie mitochondriale découverte à l'occasion d'une ophtalmoplégie externe pro- 
gressive chez un patient présentant une oligospermie pourrait être à l'origine de cette infertilité masculine.

\section{DECLIN DE LA SPERMATOGENESE: L'HYPOTHESE "ETHERS DE GLYCOL".}

\section{A. Cicolella}

Institut National de l'Environnement Industriel et des Risques Parc de Saurupt 54042 Nancy Cedex.

Les Éthers de Glycol (EG) forment une famille de substances chimiques dont l'usage s'est développé de façon importante au cours des dernières décennies. On les trouve dans les produits à usage industriel et domestique: peintures (une peinture sur 3), encres, vernis, produits de nettoyage (lavevitre par exemple), cosmétiques, produits à usage mécanique et métallurgique (fluides hydrauliques par exemple), pesticides... Leur développement a coïncidé avec celui des produits à l'eau, mais ils ont aussi été utilisés dans les produits dits "à solvants"[1]. Sur les 1800 substances produites ou importées dans l'Europe des 12 à plus de 1000 tonnes, 19 sont des EG. Le monde occidental (Europe Occidentale, USA, Japon) en a consommé 700000 tonnes en 1988 et les prévisions pour 1993 étaient de 880000 tonnes.

Jusqu'au début des années 1980, ils étaient considérés comme des substances très peu toxiques, en raison de leur très faible toxicité aiguë. Les travaux de NAGANO et coll.[2], ont montré qu'un certain nombre d'entre eux étaient des toxiques de la reproduction, du développement et du sang. Les effets observés chez toutes les espèces testées (souris, rat, cobaye, hamster, lapin, singe) sont de même nature, mais d'intensité variable selon les espèces et les EG. Ce sont principalement des éthers de l'éthylène glycol et certains isomères du propylène glycol qui induisent ces effets en raison de leur transformation métabolique en aldéhyde, puis en acide. Il a été montré que ces métabolites sont les molécules responsables des effets toxiques observés.

Les expositions mesurées au plan professionnel peuvent être supérieures aux seuils de non-effet chez l'animal, principalement en raison de la forte pénétration cutanée des EG. L'homme apparait, de plus, comme l'espèce la plus sensible en raison d'un temps d'élimination des métabolites acides plus long que chez les espèces animales testées. Dans des cas d'expositions quotidiennes, cela se traduit par une imprégnation permanente, y compris pendant le week end. La question d'une exposition via l'environnement est posée à partir de la publication d'une étude montrant la présence d'éthers de glycol dans la nappe phréatique autour de décharges industrielles.

Chez l'homme, les études publiées ces dernières années confirment les données de l'expérimentation animale: azoospermie chez des peintres en chantiers navals [3] et chez des ouvriers fondeurs [4] exposés à l'Ethyl Glycol et à son acétate. Une étude menée chez les consultants d'une clinique d'infertilité [5] trouve une relation significative entre l'imprégnation en acide éthoxyacétique, métabolite spécifique de l'éthyl glycol et de son acétate, et une atteinte du spermogramme. $3 \%$ de la population examinée avait un métabolite des éthers de glycol dans l'urine alors que le taux physiologique est nul et qu'il n'existe pas de sources connues dans l'alimentation et les médicaments.

Au vu de ces données, on peut penser qu'une partie de l'atteinte de la spermatogenèse actuellement constatée dans les pays développés [6] [7] pourrait être la conséquence de l'utilisation ubiquitaire de ces substances depuis plusieurs décennies. Un développement des études épidémiolo- 
giques prenant en compte l'exposition professionnelle et domestique (via les produits de consommation et l'eau) ainsi que des études sur la relation exposition-effet apparaît donc hautement souhaitable.

\section{REFERENCES}

1. CICOLELLA A. Les éthers de glycol. État actuel des connaissances. Perspectives de recherches. Cahiers de Notes Documentaires $\mathrm{n}^{\circ} 148$ 3eme trim. $1992 \mathrm{pp} \mathrm{1-20.}$

2. NAGANO K., NAKAYAMA E., KOYANO M., OOBAYASHI H., ADACHI H., YAMADA K (1979) Testicular atrophy of mice induced by ethylene glycol monoalkyl ethers. Jap. J. Ind. Health 21, pp 29-35.

3. WELCH LS., SCHRADER SM., TURNER TW., CULLEN MR., (1988) Effects of exposure to ethylene glycol ethers on shipyards painters. II Male reproduction. Am. J. Ind. Med. 14, pp 509-526.

4. RATCLIFFE JM., SCHRADER SM., CLAPP DE., HALPERIN WE., TURNER TW., HORNUNG RW. (1989) Semen quality in workers exposed to 2-ethoxyethanol. Br. J. Ind. Med. $46, \mathrm{pp} \quad 399-406$.

5. VEULEMANS H., STEENO O., MASSCHELEIN R., GROESENEKEN D. Exposure to ethylene glycol ethers and spermatogenic disorders in man: a case-control study. Brit. J. Ind. Med. 1993, 50, pp 71-78.

6. AUGER J., KUNSTMAN JM., CZYGLIK F., JOUANNET P. Decline in semen quality among fertile men in Paris during the past 20 years. New Engl. J. Med. 1995,332,5, pp 281-285.

7. CARLSEN E., GIWERCMAN A., KEIDING N., SKAKKEBAEK N.E. Evidence for decreasing quality of semen during past 50 years BMJ 1992,305, pp 609-613.

\section{CONDUITE A TENIR DEVANT UNE NECROZOOSPERMIE}

C. Barthelemy ${ }^{1}$, L. Nduwayo ${ }^{2}$, S. HamaMAH ${ }^{1}$, M.J. ThaRANNe ${ }^{1}$, P. LECOMTE ${ }^{2}$

1 Unité de reproduction, CHU Bretonneau 37044 Tours cedex. 2 Unité d'endocrinologie, Médecine B, CHU Bretonneau 37044 Tours cedex

La nécrozoospermie est une cause mal comprise et peu étudiée d'infertilité masculine. Son incidence parmi les sujets infertiles est estimée entre 2 et $48 \%$. Pour contribuer à la compréhension de cette anomalie, nous avons entrepris une étude rétrospective sur 3 ans portant sur une population de patients consultants au laboratoire de l'unité de reproduction du CHU de Tours.

\section{Matériels et méthodes}

Les paramètres spermatiques ont été étudiés selon les critères de l'OMS: la nécrozoospermie évaluée à l'aide de la coloration à l'Eosine-Nigrosine. Ont été pris en compte les nécrozoospermies $\geq$ à $50 \%$.

\section{L'étude des dossiers}

ATCD, examen clinique, dosages hormonaux a été complétée dans certains cas par des examens complémentaires: biochimie séminale, spermoculture, ECBU, recherche d'anticorps antispermatozoïdes, microscopie électronique, biopsie testiculaire. Les patients ont été classés en groupes en fonction des étiologies : Pathologie, Anomalie du plasma séminal, Pathologie testiculaire, Hyperthermie, Infection, Anticorps antispermatozoïdes, et un groupe ou aucune étiologie n'est retrouvée.

Nous avons comparé les groupes à l'aide de tests non paramétriques .

\section{Résultats}

Sur 5049 spermogrammes effectués, 229 présentaient une nécrozoospermie $\geq$ à $50 \%$. Ces examens correspondaient à 171 
patients dont 131 étaient suivis dans notre centre. Parmi eux 28 présentaient une nécrozoospermie sur 3 spermogrammes au moins et 14 avaient une nécrozoospermie constante sur tous les examens. 18 biochimies sur 38 présentaient des anomalies, 7/80 étaient positifs pour les Anticorps antispermatozoïdes $(8,7 \%)$ et 24 FSH élevées sur 107 évoquant une atteinte testiculaire.

Dans la population totale, aucune étiologie ne se dégage d'une façon prédominante alors que les infections représentent $40 \%$ dans la population sélectionnée des 28 patients. Parmi les 14 sujets présentant une nécrozoospermie constante, une étiologie a été retrouvée dans tous les cas et les différences de vitalité étaient significatives pour la majorité des étiologies $(\mathrm{p}<0,0001)$. Le groupe "Epididymaire" et le groupe "Plasma séminal" présentaient aussi des différences significatives avec les autres sous-groupes.

63 couples sur 131 ont réalisé une FIV ( 17 grossesses), 9 ont obtenu une grossesse spontanée. Les $\mathrm{AMP}$ sans succès concernaient les groupes anticorps et FSH augmentée. Aucune corrélation n'a été mise en évidence entre le \% de vitalité et la survenue d'une grossesse.

\section{Discussion}

Cette étude permet de mettre en évidence 2 populations différentes, l'une dont la nécrozoospermie peut être passagère et l'autre dont la nécrozoospermie est constante. Les infections représentent $39 \%$ des étiologies, mais sûrement plus car la présence des anticorps antispermatozoïdes, les perturbations biochimiques et la pathologie du plasma séminal (la nécrozoospermie s'expliquerait dans ce cas par une action nocive sur les spermatozoïdes des sécrétions modifiées des glandes) peuvent être les conséquences de problèmes infectieux des organes génitaux. Par contre il n'y a pas de nécrozoospermie chez les patients à FSH élevée. Après une exploration correcte, si aucun facteur causal n'a été décelé, peut-on parler de nécrozoospermie essentielle d'origine épididymaire (anomalie du transit ou du stockage épididymaire)?

Notre étude a permis de dégager des étiologies de la nécrozoospermie, mais pas dans tous les cas, car tous les examens qui devraient conduire à un tel diagnostic d'exclusion n'ont pas été faits de façon systématique. Nous proposons donc ici une conduite à tenir pour explorer ces patients.

\section{Conduite a tenir}

La découverte d'une nécrozoospermie incite à refaire le spermogramme à distance de tout événement pouvant altérer la qualité des spermatozoïdes. La nécrozoospermie ne peut être affirmée que sur au moins deux spermogrammes et des examens complémentaires du sperme sont indispensables: Recherche d'une infection (leucospermie, spermoculture et ECBU \pm massage prostatique), Biochimie séminale complète, Recherche d'anticorps anti-spermatozoïdes dans le plasma séminal et le sérum, éventuellement la microscopie électronique, biopsie testiculaire et épididymaire si une exploration est réalisée.

Un examen clinique soigneux, étude des ATCD, exploration hormonale, complète par l'examen des glandes annexes par ultrasons (voie endorectale) est impératif.

Le traitement de toute suspicion d'infection doit être envisagé, et dans certains cas il faut recourir aux techniques de procréation médicalement assistée (PMA) IAC, FIV, ou micro-injection du spermatozoïde dans l'ovocyte (ICSI) pour obtenir la grossesse. 


\section{SUBSTITUTION DU JAUNE D'OEUF \\ PAR DES LIPOSOMES DANS LE \\ MILIEU CRYOPROTECTEUR: EFFETS \\ SUR LA FONCTION CINETIQUE ET \\ LE POUVOIR FECONDANT DES \\ SPERMATOZOIDES HUMAINS.}

\author{
B. Sion, V. Chevalier, G. Grizard, \\ D. BOUCHER
}

Service de Biologie du Developpement et de la Reproduction, Hotel-Dieu CHU, Clermont-Ferrend Cedex.

\section{Objectifs :}

L'intérêt du jaune d'oeuf comme constituant des milieux cryoprotecteurs des spermatozoïdes est bien démontré. Son action est probablement liée, pour une part, aux phospholipides et au cholestérol (chol) qui exercent un rôle protecteur sur le gamète notamment, au niveau membranaire. Le but de ce travail est de voir dans quelle mesure, le jaune d'oeuf peut être remplacé par des lipides. Pour cela, les fonctions cinétiques et les pouvoirs fécondants des spermatozoïdes congelés/décongelés dans des milieux contenant soit du jaune d'oeuf, soit des liposomes de différente nature sont comparés.

\section{Matériel et méthodes :}

Des liposomes sont préparés à partir de phosphatidylserine de cerveau de bovin (PS), de phosphatidylcholine de jaune d'oeuf (PC-JO) de PC de cerveau de bovin (PC-CB), de distearaoyl-PC (PC18) et d'un mélange (mole/mole) de PC-CB/chol.

Les spermes retenus pour l'étude ont une concentration en spermatozoïdes $>20 \mathrm{x}$ $106 / \mathrm{ml}$ et une mobilité $>50 \%$. Ils sont divisés en aliquotes et dilués (V/V) avec du milieu basal (MB: glutamine $80 \mathrm{mM}$, fructose $0,35 \%$, citrate de sodium $0,66 \%$, glycérol $14 \%$, streptomycine $400 \mathrm{mg} / 100 \mathrm{ml}$ ), du MB contenant du jaune d'oeuf ou du MB contenant des liposomes. Après dilu- tion, les mélanges sont maintenus $15 \mathrm{mn}$ à température ambiante (période d'équilibration) puis congelés dans des paillettes de $0,25 \mathrm{ml}$ à l'aide d'un minicool LC 40, selon un programme spécifique. Pour la décongélation, les paillettes sont laissées 3 $\mathrm{mn}$ à $37^{\circ} \mathrm{C}$.

La fonction cinétique des spermatozoïdes est analysée par vidéomicrographie assistée par ordinateur (ATS-40-JC Diffusion).

Le pouvoir fécondant des spermatozoïdes est apprécié à l'aide du test utilisant les ovocytes dépellucidés de hamster. Après décongélation, les spermatozoïdes sont centrifugés et capacités dans le milieu BWW supplément avec $3 \%$ de HSA pendant 3 heures. 40 ovocytes dépellucidés sont inséminés avec $2 \times 106$ spermatozoïdes; le nombre d'ovocytes pénétrés par un ou plusieurs spermatozoïdes est alors déterminé.

\section{Résultats :}

La présence de PS dans MB entraîne une forte réduction de la mobilité progressive, cette altération est plus marquée pendant la période d'équilibration que lors du processus de congélation/décongélation.

La vitalité et la mobilité des spermatozoïdes ne sont pas modifiées significativement par la présence de jaune d'oeuf, de liposomes de $\mathrm{PC}$ de différente nature ou de liposomes de PC-CB/chol dans le MB. La présence de jaune d'oeuf dans MB entraîne une augmentation de certains paramètres du mouvement (vitesse curvilinéaire, amplitude du débattement latéral de la tête) qui n'est pas retrouvée avec les différents liposomes.

Le taux de pénétration des ovocytes de péllucidés de hamster est plus élèvé $(p<0,05)$ lorsque les spermatozoïdes sont congelés dans MB contenant des liposomes de PC$\mathrm{CB} /$ chol que dans MB seul. Cette augmentation n'est pas retrouvée avec MB contenant du jaune d'oeuf ou des liposomes de PC-CB. 


\section{Conclusion :}

La substitution du jaune d'oeuf par des liposomes de PC de différente nature dans le milieu cryoprotecteur n'a pas d'effet délétère sur la fonction cinétique du spermatozoïde. Un effet bénéfique des liposomes de $\mathrm{PC}-\mathrm{CB} / \mathrm{chol}$ a pu être mis en évidence sur le pouvoir fécondant. Cet effet n'est pas retrouvé avec le jaune d'oeuf.

\section{L'HYPOTAURINE ET LA TAURINE DANS LE SPERMATOZOIDE ET LES SECRETIONS GENITALES}

\author{
P. GUÉRIN \\ Ecole Vétérinaire, Marcy l'étoile-INSA, \\ Villeurbanne
}

\section{Introduction:}

La taurine et l'hypotaurine semblent être des acides aminés importants pour la survie des spcrmatozoïdes, la capacitation, la fécondation et le développement embryonnaire. Nous avons recherché ces 2 composés dans le sperme et les sécrétions génitales de plusieurs espèces de mammifêres.

\section{Matériel et méthodes:}

Le liquide tubaire a été collecté suivant 2 techniques: la ligature de l'oviducte à ses 2 extrémités chez la lapine $(n=4)$ ct la truie $(\mathrm{n}=4)$; cathétérisme par voie haute avec ligature à l'extrémité opposée de l'oviducte chez la brebis $(n=4)$ et la vache $(n=4)$.

Les liquides de follicules préovulatoires sont récoltés par ponction échoguidée chez la femme ( $\mathrm{n}=6)$, par ponction trans-vaginale chez la vache $(n=5)$, après laparotomie chez la chèvre $(n=6)$ et la lapine $(n=8)$, et sur ovaires isolés chez la truie $(n=7)$.

Les protéines sont éliminées par microdialyse. Les acides aminés sont séparés par chromatographie d'échange d'ions (Autoanalyseur Beckman 6300), puis dosés après coloration à la ninhydrine et absorption à 570 et $440 \mathrm{~nm}$. Les temps de rétention et les rapports de coloration aux 2 longueurs d'onde permettent l'identification des pics. Le test U de Mann et Whitney a été utilisé pour les analyses statistiques.

L'hypotaurine s'oxyde spontanément en taurine. Afin d'évaluer sa stabilité dans les milieux de culture, une solution équimoléculaire de taurine et d'hypotaurine a été incubée 1 à 5 jours à $31^{\circ} \mathrm{C}$ dans le milieu $\mathrm{M}$ 16 aditionné ou non d'albumine et/ou d'acide ascorbique.

\section{Résultats:}

La chromatographie d'échange d'ions a permis l'identification et le dosage de l'hypotaurine et de la taurine. Les spermatozoïdes humains et bovins contiennent des quantités comparables de taurine. Par contre, l'hypotaurine est présente à concentration plus élevée dans le spermatozoïde de taureau $(\mathrm{p}<0,05)$. De la même manière, le plasma séminal bovin contient des quantités plus élevées d'hypotaurine $(\mathrm{p}<0,01)$ que le plasma séminal humain.

Dans le liquide tubaire des 4 espèces étudiées, la taurine et l'hypotaurine sont présentes à des concentrations de 47 a $235 \mu \mathrm{M}$ et 154 à $271 \mu \mathrm{M}$ respectivement. Dans le liquide folliculaire, les valeurs trouvées sont 23 à $58 \mu \mathrm{M}$ à 57 à $109 \mu \mathrm{M}$ respectivement. Le rapport hypotaurine/taurine est plus élevé dans le liquide folliculaire que dans le liquide tubaire chez la vache $(p<0,05)$ et chez la truie $(p<0,01)$, et dans le liquide tubaire par rapport au sérum ( $p<0,05$ pour la vache, la truie et la lapine).

Le dosage de la taurine et de l'hypotaurine, après 5 jours d'incubation dans le milieu M16 seul ou en présence d'albumine et/ou de vitamine $\mathrm{C}$, montre que l'hypotaurine n'est pas oxydée en taurine après ce délai.

\section{Discussion:}

Nous avons trouvé des taux élevés d'hypotaurine et de taurine dans les spermato- 
zoïdes et le plasma séminal d'homme et de taureau. Dans les spermatozoïdes et le plasma séminal, le rapport hypotaurine/taurine est respectivement 5 et 17 fois plus élevé chez le taureau que chez l'homme. Cette constatation doit être raprochée de la plus grande mobilité, viabilité et fécondité du spermatozoïde bovin par rapport au spermatozoïde humain. Elle suggère que l'hypotaurine pourrait jouer un rôle important dans la fécondité du spermatozoïde. L'hypotaurine a une activité anti-oxydante à la concentration de $10 \mu \mathrm{M}$. Ainsi l'hypotaurine présente dans les sécrétions génitales pourraient avoir une activite protectrice pour les gamètes et pour l'embryon. Nos résultats montrent que ces composés sont présents en permanence dans l'environnement des spermatozoïdes quelle que soit l'espèce étudiée. L'hypotaurine pourrait être ajoutée aux milieux utilisés pour la FIV. Les concentrations d'hypotaurine sont plus élevées dans les sécrétions génitales que dans les sérums correspondants. Ceci suggère l'existence d'un transfert sélectif d'hypotaurine dans les sécrétions génitales à partir du sérurn et/ou une synthèse et sécrétion locale par les épithéliums génitaux.

\section{SYNTHESE D'HYPOTAURINE ET DE TAURINE PAR LES SPERMATO- ZOIDES ET LES CELLULES TUBAIRES}

\author{
P. GuÉRIN \\ Ecole Vétérinaire, Marcy l'étoile-INSA, \\ Villeurbanne
}

\section{Introduction:}

La taurine (acide 2-aminoéthane sulfonique) est le principal produit du métabolisme terminal de la cystéine. Avec son précurseur l'hypotaurine (acide 2-aminoéthane sulfinique), elle semble intervenir dans la maturation finale des gamètes et dans leur protection contre les radicaux libres oxygénés. Une des voies de synthèse de l'hypotaurine passe par l'acide cystéine sulfinique (CSA) qui est décarboxylé par la cystéine sulfinate décarboxylase (CSD; EC 4.1.1.29). Nous avons montré précédemment que la taurine et l'hypotaurine sont présentes en quantités importantes dans les spermatozoïdes et les sécrétions génitales. Le ler objectif de ce travail est de déterminer si la taurine et l'hypotaurine présentes dans le liquide tubaire sont le résultat d'un transfert sélectif à partir du plasma et/ou d'une synthèse locale. Le second objectif est de déterminer quelle est la voie de synthèse de ces composés dans les cellules tubaires et dans les spermatozoïdes.

\section{Matériel et Méthodes}

La synthèse de taurine et d'hypotaurine par les spermatozoïdes et par les cellules tubaires en culture a été mise en évidence en incubant des spermatozoïdes de taureau et des cellules épithéliales d'oviducte de vache et de chèvre avec de la Méthionine35S. Les cultures de cellules tubaires sont obtenues selon la méthode de Ouhibi (1989). La Taurine-35S et l'Hypotaurine-35S sont identifiées à l'aide d'un chromatographe d'échange d'ions (Beckman 6300) couplé à un détecteur de radioactivité (Flow one beta).

- La sécrétion de taurine et d'hypotaurine par les cellules tubaires en culture a été mise en évidence en idendifiant et en dosant ces composés dans le milieu conditionné de ces cultures. L'action de la vitamine $\mathrm{C}$ sur cette sécrétion a été testée.

- L'activité Cystéine Sulfinate Décarboxylase (EC 4.1. .29) a été recherchée dans les cellules épithéliales tubaires.Les cellules sont lysées par sonication dans un tampon phosphate. La CSD est immunocaptée à l'aide d'un antisérum anti-CSD spécifique (Almarghini et al.. 1994), dont les immunoglobulines sont fixées sur des particules de 
protéine A-sépharose (LEGAY et al., 1987). L'activité enzymatique est ensuite détectée en mesurant par chromatographie d'échange d'ions 1a formation d'hypotaurine, le produit de la réaction enzymatique, après incubation avec l'acide cystéine sulfinique, le substrat de l'enzyme (TAPPAZ et al., 1992).

\section{Résultats}

Nous avons mis en évidence la synthèse de l'hypotaurine et de la taurine, à partir de la méthionine, par les spermatozoïdes de taureau et par les cellules tubaires de chèvre. L'hypotaurine et la taurine sont présentes dans le milieu conditionné des cultures de cellules épithéliales tubaires de vache, de truie, de lapine et de chèvre. Chez la lapine cette présence est vitamine C-dépendante. Nous avons mis en évidence une activité CSD dans les cellules épithéliales tubaires de vache et de chèvre in vitro. Cette activité enzymatique n'a pas été mise en évidence dans les spermatozoïdes de taureau.

\section{Discussion}

Les cellules épithéliales tubaires de chèvre, de vache, de truie et de lapine sécrètent la taurine et l'hypotaurine in vitro. Il est possible que 1a vitamine $\mathrm{C}$ présente dans le liquide folliculaire induise la sécrétion de taurine et d'hypotaurine par les cellules tubaires de lapine. Pour la lère fois une activité CSD a été mise en évidence dans l'appareil génital de mammifères L'hypotaurine et la taurine sont synthétisées et sécrétées par l'épithélium tubaire via la voie de l'acide cystéine sulfinique. L'hypotaurine et la taurine présentes dans les sécrétions génitales sont donc au moins partiellement le résultat d'une synthèse locale. La présence de la CSD dans l'embryon est en cours d'étude.
METABOLISME ENERGETIQUE DU SPERME HUMAN PENDANT LA CAPACITATION: ETUDE PAR RESONANCE MAGNETIQUE NUCLEAIRE DU 31P (RMN-31P)

S. Hamamah, F. Seguin*, D. Royere, C. Barthelemy, S. Akoka*, F. Perrótin, J. LANSAC

Unité de Biologie de la Reproduction, Dept de Gynéco-Obs, Faculté de Médecine, CHU Bretonneau, F-37044, Tours * Labo de Bioph Cell \& RMN-INSERM U316, Faculté de Médecine, F-37032, Tours

\section{Introduction}

L'énergie et le profil métabolique jouent un rôle important pour gérer puis assurer la vitalité et la mobilité des spermatozoïdes. Dans cette étude, nous avons déterminé par Resonance Magnétique Nucléaire du phosphore (RMN-31P) des marqueurs énergétiques tels que le Phosphore inorganique (PI), le Phosphomonoester (PM), le Phosphodiester (PD), la Phosphocréatine (Pcr) et l'Adénosinetriphosphate $\mathrm{g}, \mathrm{a}, \mathrm{b}$ (ATP). Ces marqueurs sont la cible des changements métaboliques que les spermatozoïdes subissent lors de la capacitation.

\section{Matériels et Méthodes}

Les spermatozoïdes de patients $(n=20)$ participant à une tentative de FIV ont été lavés puis incubés à $37^{\circ} \mathrm{C}$ dans du milieu Look's contenant du Glucose ou Look's supplémenté avec $20 \%(\mathrm{v} / \mathrm{v})$ de lactate, fructose, liquide folliculaire ou calcium ionophore A23187. Les spectres RMN du 31P ont été obtenus à $200 \mathrm{MHz}$ sur un spectromètre AM 200 WB (BRUKER) équipé d'une sonde de $5 \mathrm{~mm} 1 \mathrm{H} / 31 \mathrm{P}$ à partir de $0,4 \mathrm{ml}$ de suspention spermatique. Les mesures ont été réalisées par détermination de l'intensité des pics. Les valeurs ont eté représentées en termes de moyenne $\pm \mathrm{SEM}$. 


\section{Resultats}

Le liquide folliculaire induit une augmentation de l'intensité des pics de l'ATP des spermatozoïdes en comparaison avec les spermatozoïdes incubés avec le lactate, le fructose ou le calcium ionophore (ATP : 23,7 $\pm 2,2$ versus $17,4 \pm 2,9,16,2 \pm 1,5$ et $19,2 \pm$ 2,2 respectivement). La supplémentation du milieu avec le liquide folliculaire induit une augmentation du $\mathrm{pH}$ interne ( $\mathrm{pHi}$ ) des spermatozoïdes par rapport au témoin ( $\mathrm{pHi}$ : $7,43 \pm 0,2$ versus $7,01 \pm 0,1$ respectivement). Une telle valeur augmente de 0,4 unité sous l'effet de la progestérone.

\section{Conclusion}

Les résultats obtenus dans cette étude montrent qu'il est possible d'évaluer le profil énergétique des spermatozoïdes humains de façon fiable et répétitive malgré la grande hétérogénéité des spermes. Cette étude démontre l'importance de la RMN-31P dans l'exploration de la voie métabolique du sperme. Une telle analyse devrait permettre d'élucider des altérations métaboliques que les spermatozoïdes subissent lors de la préparation pour féconder l'ovocyte.

IMPLICATION DE L'ANION SUPEROXYDE DANS LA REACTION ACROSOMIQUE DES SPERMATOZOÏDES HUMAINS INDUITE PAR UN CALCIUM IONOPHORE

\author{
JF. GRIVEAU, P. RENARd, D. Le LanNoU
}

\section{C.H.U. de Rennes}

\section{Introduction}

Les spermatozoïdes humains sont extrêmement sensibles au stress oxydatif du fait de leur contenu important en acides gras polyinsaturés et de la faiblesse de leurs défenses enzymatiques. De très récentes études ont cependant montré que des dérivés oxygènes, anion superoxyde et/ou peroxyde d'hydrogène, joueraient un rôle important dans le contrôle de certaines fonctions du spermatozoïde telles que la capacitation et/ou la réaction acrosomique. Le but de ce travail a été d'étudier l'implication de l'anion superoxyde dans ces dernières.

\section{Méthodes}

Après séparation sur gradient de Percoll, les spermatozoïdes provenant d'hommes fertiles ont été capacités pendant 6 heures a $37^{\circ} \mathrm{C}$ sous $5 \%$ de $\mathrm{CO} 2$ en présence ou non de superoxyde dismutase $(\mathrm{SOD}, 500 \mathrm{U} / \mathrm{ml})$. La réaction acrosomique a ensuite été induite par $10 \mu \mathrm{M}$ de calcium ionophore A23 187 . La production d'anion superoxyde ainsi que le taux de réaction acrosomique ont alors été mesurés. L'analyse des acides gras des spermatozoïdes mis en présence d'anion superoxyde a également été réalisée.

\section{Résultats}

L'addition de calcium ionophore entraîne à la fois une augmentation de la production d'anion superoxyde par les spermatozoïdes de l'ordre de 4 à 5 fois et une augmentation du taux de la réaction acrosomique. La présence de SOD dans le milieu d'incubation ne permet plus de détecter de production d'anion superoxyde et entraîne une réduction significative de la réaction acrosomique. Cette diminution est identique, que l'addition de SOD ait lieu au début du processus de capacitation ou seulement $15 \mathrm{~min}$. avant l'induction par le ionophore calcique. La présence de vitamine $E$, nettoyeur intramembranaire de radicaux libres, induit également une baisse significative du taux de réaction acrosomique induite. Tandis que le niveau de réaction acrosomique spontanée n'est pas augmenté en présence d'anion superoxyde, une libération d'acides gras membranaires non estérifiés est observée. 


\section{Conclusion}

Ces résultats suggèrent que la production d'anion superoxyde par les spermatozoïdes humains pourrait être impliquée dans la réaction acrosomique induite par le ionophore calcique A23 187, peut être à travers une déesterification des phospholipides qui, en augmentant la fluidité membranaire à travers l'action déstabilisante des lysophospholipides formés, augmenterait sa fusiogénicite et permettrait ainsi les différents événements associés à la réaction acrosomique ainsi qu'à la fécondation.

\section{ANOMALIES DE LA STRUCTURE CHROMATINIENNE DES SPERMATO- ZOIDES HUMAINS DETECTEES PAR LA CYTOMETRIE DE FLUX A L'ACRI- DINE ORANGE.}

\author{
Y. SOFFER ${ }^{1}$, R. GOLAN ${ }^{2}$, L. SHOCHAT ${ }^{2}$, \\ R. WEISSENBERG ${ }^{3}$, LM. LEWIN ${ }^{2}$
}

1 Centre d'Infertilité Masculine, Centre Médical Assaf Harofe ; 2 Service de Biolchimie Clinique, Faculté de Médecine Sackler, Université de Tel Aviv ; 3 Institut d'Endrologie, Centre Médical Sheba. Tel Aviv, Israël

\section{Introduction}

Alors qu'il est possible, de nos jours, de féconder des ovocytes par l'injection intracytoplasmique du sperme, il est nécessaire de développer des moyens d'exploration permettant d'évaluer l'intégrité des structures intranucléaires des spermatozoïdes humains.

\section{Méthodes}

Dans cette étude, la chromatine spermatique humaine d'échantillons normaux et anormaux été édudiée par la méthode de cytométrie de flux à l'acridine orange d'Evenson DP (Meth in Cell Biol.
1990;33:401-10) et à l'aide d'un procédé original de traitement des donnés. L'acridine orange émet une fluorescence verte avec l'ADN à double bande et une fluorescence rouge avec l'acide nucléique à bande unique. L'un des avantages de la cytométrie de flux est d'obtenir des donnés distinctes pour chaque spermatozoïde d'un même échantillon ainsi que la valeur moyenne pour tous les spermatozoïdes.

\section{Résultats}

Dans l'aire de dispersion obtenue en fonction de la fluorescence émise, rouge ou verte, 80 à $90 \%$ des spermatozoïdes d'échantillons humains normaux selon l'OMS, tombent dans une bande bien définie. 65 à $80 \%$ d'entre eux se resserrent dans une zone compacte (Créneau) analogue à celle décrite pour le sperme du hamster (Yossefi S et al. Molec Reprod Develop 1994;37:93-8). Des échantillons de sperme contenant un taux élevé d'anomalies morphologiques donnent souvent des modes de dispersion caractéristiques d'anomalies structurales diverses de la chromatine spermatique :

1. un taux bas de cellules dans le créneau normal,

2. un taux faible de cellules dans la bande normale,

3. un taux élevé de spermatozoïdes à fluorescence accrue, suggérant moins de chromatine décondensée,

4. une proportion accrue de spermatozoïdes à fort quotient de fluorescence rouge/verte suggérant un accroissement des formes immatures et, ou

5. une zone proéminente de matière à très faible fluorescence, très suggestive d'un sperme surcondensé.

\section{Conclusion}

A la lumière de ces résultats, il ressort que la cytométrie de flux est un moyen de valeur pour l'étude de la structure nucléaire du sperme. 
Des études sont actuellement menées pour élucider la nature des divers défauts de la chromatine et leurs implications dans l'infertilité du mâle.

\section{IDENTIFICATION DES STADES PRE- COCES DE LA SPERMATOGENESE DANS DES EJACULATS D'HOMMES HYPOFERTILES PAR L'UTILISATION D'UN ANTICORPS MONOCLONAL ANTI-PROACROSINE}

\author{
Soulez B., Volle P., Leroy-billiard M., \\ Hermand E., Défossez A.
}

Service de Pathologie de la Reproduction, Maternité Salengro, CHRU de Lille.

L'identification des stades précoces de la spermatogénèse dans le sperme est difficile avec les colorations classiques. A notre connaissance aucune technique ne permet de définir de manière précise la nature de ces cellules dans les éjaculats. Shrevel et coll. [1] ont décrit, en utilisant des biopsies testiculaires, l'expression de proacrosine par les cellules spermatiques dès le stade spermatocyte I et nous avons utilisé ce marqueur pour identifier les cellules germinales retrouvées dans le sperme de certains patients hypofertiles.

Les cellules rondes observées dans le sperme ont été isolées sur gradient de Percoll à partir d'éjaculats traités en vue de FIV ou d'IIU. Après lavage, les isolats déposés sur lame ont été testés avec l'anticorps 4D4 (immuno-cytochimie indirecte) et contre colorés au May Grunwald Giemsa.

La mise en évidence de proacrosine associée à l'observation de critères morphologiques, nous a permis une identification précise des cellules germinales jeunes retrouvées dans certains éjaculats.

Par ailleurs l'expression de proacrosine dans des cellules morphologiquement anormales, atypiques par leur taille ou leur rapport nucléo-cytoplasmique, parfois multinuclées, permet de rattacher ces cellules à la lignée spermatique et de préciser les anomalies de la spermatogénèse chez ces patients infertiles.

L'anticorps utilisé a été obtenu par l'équipe D. ESCALIER. J.M. GALLO, M. ALBERT, G. DAVID, J. SCHREVET et sa production stabilisée à bioMérieux. (1) J.REPROD. Fertil, 1994, 100:567-575

\section{MARQUAGE DES SPERMATOZOIDES HUMAINS AVEC DEUX FLUORO- CHROMES: APPLICATION AU TEST D'ATTACHEMENT DES SPERMATO- ZOIDES A LA ZONE PELLUCIDE D'OVOCYTES HUMAINS NON FECONDES}

\author{
R. Levy, C. Clavel, F. Eustache,
} M. Benchaib, J. LoRnage, M. C. Pinatel, H.CORDONIER, J. F. GUÉRIN.

Laboratoire de Biologie de la Reproduction et du Développement. Hôpital Edouard Herriot, Place d'Arsonval, 69437 LYON CEDEX 03

\section{Introduction}

Mettre au point et valider une technique simple de marquage des spermatozoïdes humains avec deux fluorochromes, la fluorescéine (FITC) et la rhodamine (TRITC), selon le protocole de Parrish et Foote (Biol. Reprod.1985), puis appliquer ce marquage au test d'attachement des spermatozoïdes à la zone pellucide d'ovocytes humains non fécondés 48 heures après fécondation in vitro (FIV), soit frais, soit après conservation en solution hypersaline (Liu, Fertil. Steril. 1988). 


\section{Matériel et Méthodes}

45 spermes ont été étudiés. Les spermatozoïdes sélectionnés après gradient de Percoll et lavés ont été marqués avec 2 solutions de fluorochromes (FITC et TRITC) pures ou diluées au $1 / 4$. Une analyse du mouvement a été réalisée sur les spermatozoïdes ainsi traités avant et après marquage par les 2 fluorochromes (analyseur d'images ATS 20, de J.C.Diffusion International).

Analyse statistique : test non paramétrique de Wilcoxon.

\section{Résultats}

Lors de la mise au point du marquage des spermatozoïdes, une toxicité attribuée aux fluorochromes a été observée pour des spermes de concentration $<$ à 40 millions $/ \mathrm{ml}$. Cette toxicité a pu être corrigée en utilisant une solution de fluorochrome diluée au 1/4.

Le marquage des spermatozoïdes humains par les 2 fluorochromes utilisés à des concentrations adéquates n'altère pas de façon significative les différents paramètres de la mobilité (ATS 20): vitesse curvilinéaire, amplitude de la tête, linéarité et de l'activation.

\section{Discussion - Perspective}

L'innocuité des fluorochromes et l'absence de modifications significatives des caractéristiques de la mobilité après marquage des spermatozoides humains présentent un intérêt majeur pour l'étude de l'étape essentielle que constitue l'attachement des spermatozoïdes à la zone pellucide des ovocytes. Ce test est en cours de validation dans notre laboratoire.

Les premiers tests effectués ont permis de comparer les capacités d'attachement à la zone pellucide d'un sperme "test", marqué par l'un des fluorochromes à celles d'un sperme normal "contrôle", marqué par l'autre fluorochrome. Ce test présente éga- lement l'intérêt de permettre l'étude de l'effet d'une substance sur l'aptitude des spermatozoïdes à fixer la zone pellucide des ovocytes.

\section{MISE EN EVIDENCE ET LOCALISA- TION DE RECEPTEURS AUX CYTO- KINES A LA SURFACE DES SPERMA- TOZOIDES HUMAINS}

P. SchWED*. R. Fierro ${ }^{\circ} \bullet$, B. Gobert $\Delta$, B.

Foliguet $\bullet$, MC. Bene $\Delta$, G. Faure $\Delta$

- Laboratoire d'Histologie-Embryologie, Faculté de Médecine, NANCY, FRANCE

$\triangle$ Laboratoire d'Immunologie, Faculté de Médecine, NANCY, FRANCE

*Service de Gynécologie, Hopital BIKOURHOLIM, JERUSALEM, ISRAEL

${ }^{\circ}$ Depto. Ciencias de la Salud, U.A.M.-I, CONACYT, MEXICO, MEXIQUE

\section{Introduction}

Le liquide séminal humain contient des cytokines à une concentration significative. Le rôle de ces substances reste encore hypothétique, mais la possibilité d'une action sur les fonctions des gamètes mâles n'est pas exclue. Ceci impliquerait toutefois la présence de récepteurs aux cytokines à la surface des spermatozoïdes.

\section{But du travail}

Nous avons recherché, dans cette étude, la présence et la localisation des chaînes de plusieurs récepteurs aux cytokines au niveau de la membrane des spermatozoïdes humains: IL2R, IL2R $\beta$, IL6R, de l'IFNyR et la chaîne $\beta$ commune aux récepteurs de l'IL3, de l'IL5 et du GM-CSF.

\section{Matériel et méthodes}

Les observations ont porté sur 20 spermes humains frais et traités par Percoll. Les 
spermatozoïdes ont été incubés avec des anticorps monoclonaux (CD25,CD122) ou polyclonaux (CD126, GP130, CD119) non conjugués puis avec respectivement $d u$ sérum anti-immunoglobulines de souris ou de lapin conjuguées à la fluoresceine. Après le dernier lavage, les suspensions cellulaires étaient fixées au paraformaldehyde, puis analysées en cytométrie de flux. Une partie des échantillons a été ensuite examinée en microscopie UV.

Sur deux pools de spermatozoïdes centrifugés (sperme frais et après gradient de Percoll), une étude immunochimique a été pratiquée pour déterminer les caractéristiques moléculaires des chaînes identifiées en immunofluorescence .

La localisation des récepteurs a été par ailleurs précisée en microscopie électronique à transmission, sur des coupes fines obtenues après inclusion dans le bioacryl des spermatozoïdes fixés et lavés. La fixation des anticorps a été révélée par la protéine A marquée à l'or colIoïdal.

\section{Résultats}

Les études cytométriques montrent l'expression sur les spermatozoïdes des chaînes des récepteurs aux cytokines caractérisés par les 5 anticorps spécifiques marqués. L'intensité du marquage est faible mais significative. La microscopie UV indique que les anticorps se fixent essentiellement sur la pièce intermédiaire du gamète, localisation précisée en microscopie électronique.

L'intensité du marquage est identique en cytométrie de flux avant et après Percoll. Il existe une relation inverse entre le pourcentage de spermatozoïdes marqués et la numération, et entre l'intensité de fluorescence et la mobilité à 3 heures.

Pour 4 des 5 anticorps (CD122 exclu) les études en immunoprécipitation et immunochimie permettent de retrouver une bande dont le poids moléculaire est celui des chaînes des récepteurs recherchées.

\section{Discussion et conclusion}

Ces études montrent la présence de récepteurs aux cytokines au niveau de la pièce intermédiaire des spermatozoïdes humains. Des résultats récents suggèrent le rôle de cette partie du gamète dans la régulation du taux des radicaux libres. Les cytokines (du plasma séminal, mais aussi du tractus génital féminin) pourraient ainsi intervenir par l'intermédiaire de ces récepteurs membranaires dans la préparation fonctionnelle du spermatozoïde à la capacitation et à la réaction acrosomique.

\section{ANTIGENES DE MEMBRANE DEFI- NIS PAR LES ANTICORPS ANTI- SPERMATOZOIDES DE CLASSE IgA et IgG}

\author{
J. Auer., M. De Almeida, P. Jouannet
}

Laboratoire de Biologie de la Reproduction, hôpital Cochin-Port-Royal

123 Bd de Port-royal, 75014 PARIS

\section{Introduction}

De nombreuses études menées ces dernières années ont tenté d'identifier les antigènes, cibles des anticorps anti-spermatozoïde, responsables de certaines infertilités masculines. Des techniques utilisant des anticorps sériques ont été le plus souvent employées dans ces études, mais elles comportent le risque d'identification d'antigènes ubiquitaires, souvent sous-membranaires, non impliqués dans l'infertilité. L'intégrité membranaire du spermatozoïde étant conservée jusqu'à sa rencontre avec l'ovocyte, seuls les antigènes présents sur la membrane de spermatozoïdes peuvent être les cibles fonctionnelles des anticorps. Afin d'isoler des anticorps dirigés contre les antigènes de surface, nous avons absorbé les 
sérums avec les spermatozoïdes mobiles d'hommes fertiles et nous avons élué les anticorps ensuite. Nous savons maintenant, que la réponse immune détectée au niveau sérique ne réflète pas toujours la situation au niveau local, c'est-à-dire dans l'éjaculat, ni en titre, ni en classe d'anticorps, ni même dans la topographie de fixation des anticorps sur les spermatozoïdes. Il nous a donc paru essentiel de travailler avec les anticorps élués à partir des spermatozoïdes éjaculés, puisque ce sont les seuls à être effectivement impliqués dans l'infertilité.

\section{Matériels et Méthodes}

Nous avons testé des éluats spermatiques de 11 sujets dont l'infertilité était d'origine immunologique et qui présentaient les anticorps des deux classes, IgA et IgG. Par ailleurs, nous avons analysé des éluats sériques de 8 de ces hommes. Des préparations membranaires totales obtenues à partir des spermatozoïdes normaux ont été solubilisées en $2 \%$ de SDS et séparées en SDS-PAGE en gel de $12 \%$. Le transfert a été effectué en conditions renaturantes sur membrane de PVDF et les protéines révélées par immunodétection en chimioluminescence.

\section{Résultats}

Les anticorps élués des spermatozoïdes reconnaissent 18 protéines entre 18 et 110 $\mathrm{kDa}$. Trois zones protéiques, 19/18, 68/64 et $37 / 36 \mathrm{kDa}$ sont reconnues par 11,10 et 9 sujets respectivement. Les anticorps sériques spécifiques de membrane révèlent avec une plus grande fréquence les zones de $68 / 64,37 / 36$ et certaines protéines $<25 \mathrm{kDa}$.

\section{Discussion}

L'étude comparative des protéines révélées par les éluats spermatiques et sériques nous a permis de mettre en évidence une hétérogénéité qualitative et quantitative des réponses immunes inter-individuelles. Pour chaque individu, les spécificités antigéniques définies par les anticorps circu- lants et locaux ne sont pas toujours identiques. De plus, chaque classe d'anticorps peut reconnaître les molécules-cible différentes.

Malgré cette hétérogénéité apparente, la majorité des anticorps élués et ce quelle que soit leur classe, reconnaissent fortement la zone de $19 / 18 \mathrm{kDa}$. L'isolement de ces protéines est en cours et permettra de définir son implication éventuelle dans l'interaction gamétique.

\section{INCIDENCE DE LA PRESENCE D'AU- TOANTICORPS CHEZ L'HOMME SUR LA FERTILITE DU COUPLE : ETUDE RETROSPECTIVE DU CHU DE CAEN}

E. Szerman-Joly (1) (2), N. Defenouillere. ${ }^{(2)}$ , D. Herlicoviez (1), E. Denis (1), A. Sauvalle (1), M. Herlicoviez (L), MA. DrosDowskY ${ }^{(2)}$

(1) Centre d'Assistance Médicale a la Procréation (2) Laboratoire de Biochimie CHRU Côte de Nacre 14033 CAEN Cedex

De nombreux travaux ont permis d'établir que les anticorps dirigés contre les spermatozoïdes sont susceptibles d'altérer la fertilité du couple. Chez l'homme l'auto-immunisation antisperme est observée dans deux situations, soit lors d'une altération du système de défense immunitaire, soit lors d'une rupture de la barrière hémo-testiculaire ou une augmentation de la perméabilité au niveau des voies efférentes. La présence d'anticorps antispermatozoïdes est la cause d'une "stérilité relative" et non pas absolue. On parlera plutôt d'hypofertilité. En effet, des divergences importantes existent entre les auteurs quant a l'incidence réelle des anticorps sur la fertilité du fait d'une part de l'hétérogénéité des anticorps réagissant contre de nombreux épitopes sur les spermatozoïdes et d'autre part de l'utili- 
sation des différentes techniques de dosage non standardisées. A l'heure actuelle, la technique des immunobilles (IBT) tend à se généraliser; elle permet à la fois la détermination de l'isotype, la topographie de fixation et le pourcentage de spermatozoïdes porteurs d'anticorps.

L'utilisation de cette technique au CHU de Caen a débuté en Janvier 1986. Nous avons pratiqué à l'occasion d'un premier bilan d'infertilité 1467 recherches d'anticorps antispermatozoïdes chez des hommes non azoospermes et dépistés 93 patients IBT positifs (taux $>20 \%$ IgG et/ou IgA, soit une incidence de 6,2\%).Parmi ceux-ci 44 présentaient un spermogramme normal. Une cause d'infertilité féminine était associée chez 40 couples.

Dans notre population, les taux d'IgG et/ou d'IgA sont supérieurs à $60 \%$ dans $77 \%$ des cas sans corrélation avec une étiologie spécifique. Le signe d'appel ayant entraîné la recherche d'auto-anticorps consiste dans 55 $\%$ des cas en un test de Hünher négatif ou pauvre. La présence d'agglutinats a été signalée le jour du dosage dans $67 \%$ des cas. Une asthénospermie ou une chute secondaire de mobilité est associée également au test IBT $(+)$ dans $55 \%$ des cas.

Parmi ces couples, 8 d'entre eux ont présenté une grossesse spontanée, 5 ont eu recours à l'IAD en première intention et 55 aux PMA (IIU et/ou FIVETE). L'analyse des résultats de FIVETE ( 34 couples) montre que le taux de segmentation des ovocytes est nettement diminué lorsque l'homme est porteur d'anticorps avec un taux d'IgG et d'IgA $\geq 60 \%$ et que la localisation des anticorps sur la totalité du spermatozoïde diminue de façon importante le pouvoir fécondant quel que soit le taux, par rapport à une localisation uniquement flagellaire.

On peut constater que dans de nombreux cas, la présence d'anticorps chez l'homme n'est pas le seul facteur intervenant dans la stérilité du couple et qu'il est nécessaire de rechercher d'autres facteurs d'infertilité. Le développement des techniques de dépistage utilisant des anticorps monoclonaux spécifiques dirigés contre des antigènes directement impliques dans le processus de liaison à la membrane pellucide permettra de sélectionner les stérilités immunologiques "vraies".

\section{ANALYSE AUTOMATISEE DU MOU- VEMENT DES SPERMATOZOIDES: REPRODUCTIBILITE ET INTERET POUR LE CHOIX D'UNE TECHNIQUE D'AMP}

\section{Fillion, M. Kraemer, B. Martin-Pont, J. GonzaLes}

Service d'Histologie Embryologie Cytogenetique, laboratoire de Biologie de la Reproduction, Hopital Jean Verdier, av. du 14 Juillet, 93143 BONDY.

\section{Introduction}

L'analyse automatisée du mouvement des spermatozoïdes apparaît aujourd'hui comme un examen important lors de l'exploration d'une infertilité d'origine masculine ou idiopathique. Dans une étude précédente nous avons en effet montre qu'il existait une corrélation entre certains paramètres cinétiques (VSL, VCL et ALH) et le taux de fécondation en FIV.

Le but de la présente étude est de vérifier la fiabilité de l'analyse automatisée du mouvement en étudiant sa reproductibilité chez un même patient pour des éjaculats différents. A partir de ces résultats, s'ils s'avèrent concordants, une stratégie thérapeutique peut être proposée.

\section{Matériel et méthodes}

32 patients ont effectué deux recueils de sperme dans un intervalle de 3 à 6 mois. 
Les paramètres cinétiques des spermatozoïdes (VSL, VCL et ALH) étudiés dans l'éjaculat et après préparation en Percoll $(90-45 \%)$ ont été déterminés avec un CASA (Cell Trak / Motion Analysis, version 3.20 ) ; ils ont été comparés entre les deux recueils. L'écart des résultats entre les deux mesures a été exprimé en pourcentage après calcul du rapport entre les deux valeurs obtenues.

\section{Résultats et discussion}

Lorsque les prélèvements sont effectués dans de bonnes conditions (recueil complet au laboratoire, délai d'abstinence de deux à trois jours, aucun signe infectieux spermatique...) les écarts entre les résultats des analyses des deux recueils sont faibles. Après préparation en Percoll, les valeurs des paramètres cinétiques montrent une excellente reproductibilité puisqu'elles ne diffèrent au maximum que de $10 \%$ dans $2 / 3$ des cas. En outre, en ce qui concerne la VCL (paramètre le mieux corrèle au taux de fécondation en FIV, $r=0,59$ ), les valeurs comparées sont très proches, leur écart étant inférieur à $20 \%$, et dans un cas sur deux les valeurs ne diffèrent pas de plus de $5 \%$.

Cette étude montre que l'analyse automatisée du mouvement des spermatozoïdes est fiable et reproductible ce qui justifie de ne pas répéter systématiquement cet examen. Du fait de l'existence d'une corrélation entre les paramètres cinétiques et le taux de fécondation en FIV, il paraît licite dans les cas d'infertilité masculine où prédominent l'oligo et/ou l'asthénospermie de réaliser une analyse du mouvement des spermatozoïdes par un CASA afin de proposer la technique d'AMP la plus appropriée.

\section{ANALYSE DU PLASMA SEMINAL HUMAIN EN SPECTROSCOPIE A RESONANCE MAGNETIQUE, EN RELATION AU TEMPS D'INCUBATION}

M. Eugene ${ }^{\circ}$, L. Le Moyec ${ }^{\circ}$, E. ERdeI*, V. Maletic*, J. TRITTO*o, G. ARVis*, A. LE Duc ${ }^{\circ}$

* Hopital Tenon, Service du Pr Gabriel Arvis, Paris, Hopital Saint-Louis, Service du Pr Alain Le Duc, Paris.

\section{Introduction}

La composition du fluide séminal est très complexe et représente le résultat d'une série de réactions enzymatiques qui se déroulent dans le même temps. La biochimie fonctionnelle du fluide séminal est très mal connue du fait des difficultés d'analyses sur une matrice très visqueuse qui demande des méthodologies analytiques de longue durée et différentes. La spectroscopie à résonance magnétique des fluides biologiques est actuellement disponible pour une utilisation de routine, elle est très rapide (10 minutes), elle n'est pas destructive du tissu, elle n'est pas réservée à une sélection à priori des produits et elle donne des informations complémentaires sur la dynamique moléculaire.

\section{Méthodes}

Des échantillons de fluide séminal d'environ 450 micro litres, prélevés sur des sujets normaux et fertiles, ont été mis dans des tubes pour spectroscopie à résonance magnétique sans aucune préparation. Les mesures ont été réalisées à $20^{\circ}$ dans un spectromètre Brucker AM400 avec une technique à pulsation isolée avec une présaturation du signal de l'eau à 15 - 30 minutes, $1,2,4,8,12$ et 24 heures après le recueil du sperme.

\section{Résultats}

Les principales composantes identifiées sont le citrate, la spermine, la glycérophos- 
phocholine (GPC), la phosphorylcholine $(\mathrm{PC})$, la choline $(\mathrm{Ch}), \mathrm{N}$-acétyl dérivés des glycoprotéines, lactate, leucine / isoleucine/valine, lysine alanine, leucine/arginine, fructose/inositol, glutamate/glutamine. L'amplitude des spectres en résonance magnétique augmente entre tl5 et $\mathrm{t} 30$ à cause de l'augmentation de la mobilité moléculaire liée à la liquéfaction du liquide. Les analyses en fonction du temps, montrent une diminution de la phosphorylcholine (PC) et une augmentation de la choline (Ch) avec un constant temporel de 180 minutes, par contre la glycérophosphocholine reste stable jusqu'à 480 minutes. Après ce délai la concentration des aminoacides augmente progressivement à cause de l'hydrolyse des protéines. La choline est métabolisée en diméthylglycine, le citrate et les sucres s'effondrent et la fermentation alcoolique apparait.

\section{Conclusion}

Les résultats préliminaires montrent des données dynamiques utilisables pour une nouvelle procédure clinique dans l'exploration de la fonction séminale. La spectroscopie à résonance magnétique protonique in vitro du fluide séminal, peut être proposée comme une technique non invasive rapide, pour évaluer les modifications dépendantes du temps d'incubation du fluide séminal et comparer aux résultats

\section{L'ASSURANCE DE QUALITE EN BIO- LOGIE DE LA REPRODUCTION : APPLICATION AU SPERMOCYTO- GRAMME}

\author{
A. Bourguignat (1), A. Clavert (2), \\ G. Ferard (1)
}

(1) Faculté de Pharmacie, Laboratoire de Biochimie Appliquée, STRASBOURG (2) CECOS, Hopitaux Universitaires de Strasbourg, STRASBOURG
L'utilisation des résultats de laboratoire dans l'aide à la décision (pronostic et/ou diagnostic) nécessite d'avoir des données fiables, donc une assurance dans la qualité d'exécution des analyses. Ceci peut être réalisé par la mise en place de confrontations inter laboratoires, chacun d'entre eux recevant et analysant des spécimens identiques.

Nous nous sommes proposés d'appliquer la démarche introduite dans les années 1975 en Biochimie à la Biologie de la Reproduction. Nous vous présentons aujourd'hui les premiers résultats de l'évolution de la cohérence des résultats pour l'examen du spermocytogramme, une des premières étapes dans l'exploration de l'infertilité masculine.

\section{Matériel et Méthodes}

37 laboratoires situés majoritairement dans le Nord-Est de la France ont accepté de participer à la mise en place d'un tel système d'autoévaluation. Les participants reçoivent deux lames préfixées provenant chacune d'un même éjaculat. La coloration est effectuée par le laboratoire selon sa technique habituelle; un certain nombre de paramètres sont étudiés (proportion de spermatozoïdes normaux, anomalies particulières de forme, indice d'anomalies multiples, ...). L'étude des résultats se fait sur l'ensemble des données rendues par les laboratoires. Pour chaque paramètre, une "zone d'acceptabilité" est définie (actuellement, elle est de $+15 \%$ autour d'une valeur cible). Compte tenu de la présence de deux échantillons, I'interpretation statistique se fait à l'aide du diagramme de Youden en termes d'exactitude et de précision.

\section{Résultats}

La période d'évaluation se situe d'avril 1992 à novembre 1994. A titre d'exemple, nous discutons l'évolution de l'indice d'anomalies multiples.

Lors de la première confrontation, la proportion de laboratoires situés dans les deux zones d'acceptabilité était de $10 \%$; en novembre 1994, elle est de $40 \%$. 
Dans le même temps, la dispersion des résultats (matérialisée par le coefficient de variation) se réduit de manière significative (de $25 \%$ a $12 \%$ environ) montrant une harmonisation des résultats.

\section{Conclusion}

Après deux années d'évaluation de la cohérence inter laboratoires des résultats de l'examen du spermocytogramme, nous avons montre l'efficacité d'une telle procédure qui devra être poursuivie et développée pour d'autres paramètres courants, utilisés dans l'exploration de l'infertilité masculine.

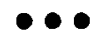

TROUBLES DE LA FERTILITE MASCULINE ASSOCIES A UN REMANIEMENT CHROMOSOMIQUE COMPLEXE: A PROPOS D'UN CAS D'AZOOSPERMIE AVEC TRANSLOCATION $T(7 ; 8 ; Y)$.

\author{
S. Briaultl, A. Guichetl, C Barthelemy \\ 2 , Cl. Morainel \\ 1: Unıté de Génétique, CHU Bretonneau, \\ 37044 Tours cedex, 2: Unité de Biologie de la \\ Reproduction, CHU Bretonneau, 37044 Tours \\ cedex.
}

Les remaniements chromosomiques équilibrés constituent une cause fréquente de troubles de la fertilité. Ces remaniements sont le plus souvent des translocations réciproques équilibrées simples qui se manifestent par des avortements spontanés répétés. En revanche, les remaniements de la structure chromosomique dépistés lors de l'exploration de troubles sévères de la spermatogenèse sont généralement à type de translocations complexes.

Nous rapportons le cas d'un sujet mascu- lin dont l'étude du caryotype effectuée lors de l'exploration d'une azoospermie a permis de caractériser une translocation réciproque équilibrée complexe impliquant un chromosome 7, 8 et $\mathrm{Y}$.

L'hybridation in situ d'une pansonde du chromosome 7 a objectivé la translocation de matériel 7q sur le bras court du chromosome 8 et sur le bras long du chromosome Y.

La mise en évidence d'un tel remaniement permet d'expliquer la présence d'une azoospermie. En effet, il est probable que la complexité de ces translocations rend impossible l'appariement méiotique, bloquant ainsi la spermatogenèse.

\section{CRYPTORCHIDIE ET INFECONDITE MASCULINE}

\author{
R. Mieusset, L. Bujan, G. Mansat, \\ A. Mansat, F. Pontonnier \\ Centre de Stérilité Masculine, Hôpital La \\ Grave, Toulouse
}

La cryptorchidie a pour conséquence possible l'infécondité. Dans le but de mieux comprendre les relations entre cryptorchidie et infécondité, plusieurs paramètres cliniques et biologiques ont été recueillis chez 85 hommes féconds et 95 hommes inféconds ayant un antécédent de cryptorchidie uni-ou bilatérale traitée médicalement ou chirurgicalement.

La cryptorchidie est associée à une réduction du volume du testicule atteint. La spermatogenèse (quantitative et qualitative) des cryptorchidies est sévèrement altérée. 
Deux facteurs de risque ont été isolés dans cette population cryptorchide :

1. l'existence d'un testicule ascenceur intermittent, qui semble plus fréquente après traitement médical que chirurgical, est associée à une production de spermatozoïdes quantitativement moindre;

2. la présence d'une température scrotale anormalement augmentée qui est associée à une réduction des volumes testiculaires, à une spermatogenèse plus altérée et à une plus grande fréquence d'infécondité primaire. 


\section{EPIDIDYME}

\section{CARACTERISATION ET IDENTIFICA- TION DE PROTEINES SYNTHETI- SEES PAR L'EPIDIDYME DE PORC}

\author{
P. Syntin.,Jl. Dacheux, F. Dacheux \\ URA INRA-CINRS 1291, PRMD \\ Nouzilly,37380 Laboratoire de Biologie de la \\ Reproduction, Sciences et Techniques, \\ Tours, 37200 .
}

Parmi les fluides de l'organisme, le milieu environnant les gamètes mâles est un milieu spécifique. Cette spécificité est rendue possible grâce à l'existence d'une barrière biologique entre le milieu sanguin et le milieu germinal. Par micro prélèvements de fluides épididymaires et néosynthèses de protéines à partir de tissus ou de tubules, nous avons pu caractériser les protéines majeures sécrétées dans l'épididyme et identifier la plupart d'entre elles.

Les protéines présentes dans les différentes parties de cet organe et les produits de néosynthèse in vitro en présence de methionine $35 \mathrm{~S}$ ont été séparés par electrophorèse bidimensionnelle. L'analyse des gels et des autoradiographies a été faite à l'aide d'un analyseur d'image adapté aux gels d'électrophorèse en deux dimensions (Système Kepler, LSB corporation)(*). Ce système permet d'effectuer des comparaisons de taches entre les différents gels et de quantifier leur surface et leur intensité.

Grâce à ce système, une cartographie complète représentant les positions électrophorétiques des différentes protéines synthétisées et sécrétées dans les différentes régions épididymaires a pu être réalisée. Cette carte contient 212 spots. Plusieurs protéines sont polymorphes ( $\mathrm{pI}$ et poids moléculaires différents). Dans ces conditions, 134 polypeptides différents ont été positionnés.
Des microséquençages de la partie N-terminale des protéines ont été réalisés à partir de transfert des séparations électrophorétiques sur membrane de nylon. Le microséquençage a été effectué sur un appareil Porton LF 3000 (BECKMAN) [1] (*). Par recherche d'homologie par le logiciel FASTA ou BLAST à partir de banques de données (Genbank, EMBL, PIR, SwissProt) plusieurs protéines ont pu être caractérisées. Ainsi parmi les protéines les plus importantes nous avons pu identifier des protéines apparentées aux glutathione-peroxidases, $\mathrm{N}$-acetyl $\beta$-hexosaminidases, mannosidases, lipocalines, procathepsines et à des protéines de rôle inconnu telle que la clusterine (SGP-2) ou ESP1.6.

Ces protéines sont les plus importantes en concentration ou en biosynthèse dans cet organe. Leurs rôles dans la physiologie du spermatozoïde ne sont pas connus.

[1] Atelier de Microséquençage des protéines, INRA, Nouzilly, 37380. (Telephone: 424778 67).

(*) Appareillages co-financés par la Region Centre et l'INRA.

\section{POLARISATION DES SECRETIONS PROTEIQUES DANS L'EPIDIDYME DE PORC : ANALYSE QUANTITATIVE}

\author{
P. Syntin, JL. Dacheux, F. Dacheux
}

Laboratoire de Physiologie de la Reproduction, Unité Associée INRA-CNRS 1291. Nouzilly, 37380

L'activité de synthèse et de sécrétion des cellules épididymaires a été analysée chez le porc par biosynthèse in vitro tout le long de l'organe dans le but : [1] de définir une spécialisation régionale, [2] de quantifier les protéines sécrétées dans les différentes 
régions et [3] de déterminer l'orientation de la sécrétion protéique dans les tubules : apicale ou basale.

Des incubations in vitro en présence de méthionine $35 \mathrm{~S}$ ont été réalisées soit à partir de fragments de tissus épididymaires soit à partir de tubules isolés porvenant de 10 régions épididymaires. Les protéines néosynthétisées, sécrétées à l'intérieur ou à l'extérieur du tube sont séparées par électrophorèse bidimensionnelle et détectée par autoradiographie. L'analyse quantitative des sécrétions a été réalisée à l'aide d'un système informatique utilisant un logiciel pour gel 2D (Kepler, LSB corporation) qui intègre la surface et l'intensité de chaque spot.

Deux types de protéines ont été identifiées selon la polarisation de la sécrétion : [1] des protéines majeures, spécifiques de l'épididyme et régionalisées sont sécrétées dans la lumière du tube par les cellules épithéliales et [2] des protéines mineures, non régionalisées sont sécrétées à l'extérieur du tube, tout le long de l'épididyme. Ces protéines communes, trouvées également dans le testicule, le rete testis et les vas efferentes, proviennent vraisemblablement d'un autre type cellulaire constituant la paroi du tube (tissu conjonctif, tissu musculaire lisse...).

En ce qui concerne les protéines majeures et spécifiques, nous avons ainsi identifié cinq régions épididymaires : la tête proximale (EO-E1), la tête médiane (E2-E3), la tête distale (E4-E5), le corps (E6-E7) et la région caudale (E8-E9). Les deux premières régions sont caractérisées respectivement par la sécrétion du train A (E0-E1) et de la clusterine (E2-E3) qui représentent chacune 70 à $80 \%$ de la sécrétion totale des protéines. Une telle intensité de sécrétion n'a jamais était décrite auparavant et semble être spécifique de l'épididyme de proc. Dans la tête distale trois composés apparaissent : les trains I (21\%), E $(4,3 \%)$ et $\mathrm{N}(10,5 \%)$. Le corps est caractérisé par deux composés majeurs : les trains $\mathrm{M}(3,3 \%)$ et $\mathrm{H}(22,4 \%)$.
Dans la région caudale aucune protéine majeure spécifique n'est sécrétée, les composés néosynthétisés sont sécrétés à l'extérieur du tube et communs aux autres régions.

Le rôle des protéines épididymaires spécifiques n'est pas clair, même pour celles ayant une activité enzymatique identifiée. Certains composés interagissent avec la membrane du gamète mais la signification de la sécrétion séquentielle des protéines épididymaires vis à vis de la maturation des spermatozoïdes n'est pas élucidée.

\section{ANALYSE QUANTITATIVE ET QUALI- TATTVE DE L'EPIDIDYME DANS LES AZOOSPERMIES EXCRETOIRES :}

\section{Approche morphométrique par analyse d'image}

\author{
F. Perrotin, S. Hamamah, D. Royere, \\ C. BARTHELEMY, G. BODY, J. LANSAC
}

Unité de Biologie de la Reproduction, Département de Gynécologie Obstétrique, CHU Bretonneau, 37044 Tours cedex

\section{Introduction}

Chez les mammifères, les spermatozoïdes à leur sortie du testicule sont incapables de féconder l'ovule, ils acquièrent leur pouvoir fécondant lors du transit dans la queue de l'épididyme. Cependant, des grossesses ont pu être obtenues chez l'homme après fécondation in vitro (FIV) ou après injection intra-cytoplasmique (ICSI) de spermatozoïdes prélevés au niveau de la tête de l'épididyme. De tels résultats posent le problème du rôle de l'épithélium du canal épididymaire dans la maturation des spermatozoïdes. Ce travail a eu pour but d'étudier quantitativement et qualitativement l'épithélium épididymaire des patients atteints 
d'une agénésie vésiculo-déférentielle (AVD) et de déterminer si la qualité de l'épithélium peut influencer la capacité des spermatozoïdes à féconder l'ovocyte.

\section{Matériel et méthodes}

Lors de prélèvements de sperme épididymaire pour la réalisation d'une FIV, des biopsies des régions du corps de la tête et de la queue de l'épididyme ont été effectuées. Des coupes semi-fines ont été préparées et étudiées par analyse d'image assistée par ordinateur (Alcatel TITN, SAMBA 2000). Le rapport des surfaces totale et luminale des coupes du tube épididymaire, l'épaisseur épitheliale et la longueur des stéréocils ont ainsi été mesurées.

\section{Résultats}

Notre étude nous a permis de distinguer, en fonction de la longueur résiduelle de l'épididyme trois groupes de patients (GI: 0,5-2 $\mathrm{cm}$, GII: $2-4 \mathrm{~cm}$ et GIII: $>4 \mathrm{~cm}$ ). Nous avons observé au niveau de la tête de l'épididyme une variation significative de chacun des trois paramètres étudiés entre les GI et GIII ( $\mathrm{p} \leq \mathrm{O}, \mathrm{Ol})$. De plus l'épaisseur de l'épithélium et la longueur des stéréocils sont significativement abaissées en l'absence de fécondation lors de FIV conventionnelle $(\mathrm{p} \leq 0,01)$.

\section{Conclusion}

Les résultats de notre étude suggèrent l'intérêt de l'analyse morphométrique de l'épithélium épididymaire dans les AVD. L'altération de paramètres tels que l'épaisseur de l'épithélium ou la hauteur des stéréocils pourrait être utilisée pour expliquer et prédire les échecs de fécondation avec sperme épididymaire.
L'ABSENCE D'UNE PROTEINE EPIDIDYMAIRE DU SPERMATOZOIDE EST ASSOCIEE A CERTAINS CAS D'INFERTILITE IDIOPATHIQUE CHEZ L'HOMME

\author{
F. BouE**, R. SUllivaN*. \\ * Service d'Histologie-embryologie orienté en Bio- \\ logie de la Reproductin - Université paris V - \\ Hôpital COCHIN - 123 Bd de Port-Royal - 75014 \\ Paris. * Dépt. Obstétrique-Gynécologie - Ontoge- \\ ny-Reproduction - Université Laval - Centre de \\ Recherche du CHUL - 2705 Bd Laurier - Ste Foy \\ - GIV 4G2 Quebec.
}

\section{Introduction}

Les modifications membranaires des spermatozoïdes au cours de la maturation épididymaire, en particulier l'acquisition de nouvelles protéines, constituent un prérequis à l'interaction des gamètes. Nous avions précédemment démontré que la $\mathrm{P} 34 \mathrm{H}$, une protéine du spermatozoïde humain d'origine épididymaire, joue un rôle dans le processus de la liaison du spermatozoïde à la zone pellucide [1].

Dans cette étude la $\mathrm{P} 34 \mathrm{H}$ a été quantifiée sur les spermatozoïdes d'hommes fertiles pour établir une valeur de référence puis chez des hommes ayant une infertilité idiopathique, afin de mettre en évidence une éventuelle corrélation entre la présence de la P34H et la fertilité masculine.

\section{Matériel et Métrhodes}

Un anticorps polyclonal spécifique de la $\mathrm{P} 34 \mathrm{H}$ a été utilisé pour réaliser des Western blots de protéines extraites d'un nombre constant de spermatozoïdes. La quantité de $\mathrm{P} 34 \mathrm{H}$ a été mesurée par densitométrie après révélation des Western blots par Chimioluminescence.

Un test de liaison des spermatozoïdes à la zone pellucide humaine a été réalisé avec les spermatozoïdes d'hommes présentant différents niveaux d'expressions de la P34H. 


\section{Résultats et Discussion}

Trois expériences réalisées de manière indépendante montrent que le niveau d'expression de la P34H est constant chez un même individu et que la quantité exprimée est similaire chez tous les hommes fertiles étudiés $(\mathrm{n}=17)$. A partir de ces résultats une valeur de référence a été déterminée $(100 \%)$. Dans la population d'hommes fertiles les valeurs varient de 58 à $133 \%$.

En comparaison avec cette population d'hommes fertiles, le niveau d'expression de la $\mathrm{P} 34 \mathrm{H}$ est de $30 \%$ ou moins chez $9 / 16$ hommes infertiles. Les autres patients ont un niveau d'expression similaire par rapport aux témoins fertiles. De plus les spermatozoïdes d'hommes ayant un faible niveau d'expression de la $\mathrm{P} 34 \mathrm{H}$ ont une très faible capacité de liaison à la zone pellucide.

\section{Conclusion}

Nos résultats montrent que le niveau d'expression de la $\mathrm{P} 34 \mathrm{H}$ sur les spermatozoïdes varie d'un homme à l'autre et que les faibles quantités de cette protéine spermatique sont associées à certains cas d'infertilités idiopathiques. La P34H pourrait être utilisée comme marqueur de la fonction épididymaire chez l'homme et servir au diagnostic de certaines infertilités inexpliquées.

(fonds CRM et FRSQ, FB boursier de la Société de Secours des Amis des Sciences).

1. BOUÉ ET COLL, 1994, Biol. Reprod. 51 : 577587

\section{ASSISTANCE MEDICALE A LA PROCREATION}

\section{EVALUATION D'UN PROTOCOLE SIMPLIFIE POUR L'INJECTION INTRACYTOPLASMIQUE D'UN SPER- MATOZOÏDE (ICSI)}

\author{
M. Jean, P. BarkiERe, S. Mirallie, \\ H. LuCAS, MF. Dubin, M. Roch \\ Laboratoire de Biologie de la Reproduction, \\ CHU de NANTES
}

\section{Introduction}

L'injection intracytoplasmique d'un spermatozoïde (ICSI) connaît un développement considérable dans le traitement des infertilités masculines sévères. Cependant, l'injection, avec le spermatozoïde sélectionné, d'une solution de polyvinylpyrrolidone (PVP) dans le cytoplasme de l'ovocyte peut présenter, en raison de la nature de ce produit, un risque toxique potentiel.

Le but de ce travail a été d'évaluer les résultats de l'ICSI en utilisant un milieu d'injection sans PVP.

\section{Matériels et Méthodes}

L'ICSI a été pratiquée au cours de 15 cycles chez des patients présentant une oligoasthénospermie sévère: numération (millions/ml): $14.7+/-13.1(1-45)$; mobilité progressive $(\%): 10.2+/-10.6(0-30)$. Les spermatozoïdes sont préparés par 2 lavages/centrifugations dans une solution saline de Tyrode. Le culot de spermatozoïdes est ensuite remis en suspension dans $0.2 \mathrm{ml}$ de B2 de Menezo et utilisé directement pour I'ICSI. La micromanipulation des ovocytes est réalisée dans du B2 qui est ainsi employé comme milieu d'injection pour le spermatozoïde sélectionné. 


\section{Résultats:}

- ovocytes recueillis :175

- ovocytes matures injectés: 130

- ovocytes intacts après l'ICSI: 121

- zygotes diploïdes: 40

- embryons transférés: 40

- taux de fécondation / ovocyte mature injecté : $33 \%$ taux de transfert / cycle: $86.6 \%$

- taux de grossesse / cycle: $13.3 \%$

- 1 grossesse gémellaire évolutive (12 SA)

- 1 avortement spontané précoce

\section{Conclusion}

Malgré la taille réduite de cette série, l'absence de PVP dans le milieu d'injection ne paraît pas affecter les résultats de l'ICSI. Bien que ces premiers résultats méritent d'être confirmés, il semble donc légitime d'éviter l'emploi du PVP pour la microinjection du spermatozoïde compte-tenu de la toxicité potentielle de ce produit.

\section{FIV OU ICSI ?}

\section{VALEUR PREDICTIVE DE DIFFE-} RENTS PARAMETRES DU SPERME

C. WITTEMER, S. WARTER*, B. SUdAN*, RM. Demand*, J. OHL, K. BetTahar-Lebugle, L. Moreau, P. Dellenbach, Y. Rumpler.

Département de PMA, Service de gynécologie-obstétrique, C.M.C.O., 67300 Strasbourg/Schiltigheim *Laboratoire de Biologie de la Reproduction, Hopital Civil, 67000 Strasbourg

\section{Introduction}

Les examens conventionnels du sperme semblent avoir une valeur pronostique limitée en ce qui concerne la réussite ou l'échec d'une PMA. Des méthodes plus objectives d'analyse permettent - elles de cibler la technique de PMA la plus adaptée à chaque couple?

\section{Matériel et méthodes}

Cette étude a été menée de mars à décembre 94 et a concerné 49 couples consultant pour infertilité primaire. L'âge moyen des femmes était de 33,3 ans (26-42), celui des hommes de 35,3 ans (29-45).

Le nombre de cellules et les paramètres cinétiques (CASA,Hamilton-Thorn HTM- S) ont été étudiés dans le sperme frais et après traitement capacitant (milieu B2-Menezo durant 5 heures). La réaction acrosomique a été analysée après induction au calcium ionophore et marquage fluorescent (FITC-PSA).

Les 49 couples de l'étude ont été inclus ultérieurement dans un protocole de fécondation in vitro. Dans tous les cas la réponse ovarienne à la stimulation a été de bonne qualité avec au moins quatre ovocytes matures recueillis.

\section{Résultats}

D'après les résultats des tentatives de FIV, les couples ont été répartis en deux catégories: les "féconds": obtention d'embryons dès le premier cycle et les "inféconds": aucune fécondation après deux voire trois cycles.

Pour tous les spermes 29 variables ont été analysées (analyses pré-FIV). La population a été classée en deux groupes à l'aide de l'analyse multifactorielle discriminante (STATITCF) qui a permis de mettre en évidence 7 variables paraissant les plus discriminantes : paramètres cinétiques dans le sperme frais l.VSL 2 . VCL 3 . ALH paramètres de la réaction acrosomique: 4 . pourcentage de spermatozoïdes intacts après induction, 5. différence entre le nombre de spermatozoïdes intacts avant et après induction par le calcium, 6. pourcentage de spermatozoïdes présentant après induction une réaction acrosomique de type équatorial et 7 . de type terminée. 
Le classement effectué à partir de ces 7 variables correspond au classement réel "féconds / inféconds" dans $69,4 \%$ des cas.

\section{Discussion}

Dans nos conditions de travail les paramètres les plus prédictifs sont certains les paramètres cinétiques du sperme frais et l'étude de la réaction acrosomique.

Ces paramètres permettent une orientation plus appropriée vers l'une ou l'autre technique de PMA (FIV ou ICSI) pour optimiser les chances de grossesse des couples infertiles.

\section{ETUDE DES FACTEURS PREDICTIFS D'ECHECS REPETES DE FECONDA- TION IN VITRO.}

H . Le Jeune *, C. ERibon, D. Boulieu, V. Bied, F. Payan, M Pugeat*, JC. Czyba, JF. GUERIN

Fédération "Femme Mére Nouveau-né", Hopital Edouard Herriot et *Clinique Endocrinologique, Hopital de l'Antiquaille, Lyon.

L'injection intra-ovocytaire d'un spermatozoïde (ICSI) reconnaît 2 types d'indications, des altérations très sévères du spermogramme ne permettant pas de réaliser une fécondation in vitro (FIV) classique et les échecs de fécondation lors de tentative(s) antérieure(s) de FIV classique. Pour préciser les indications de recours à l'ICSI après un premier échec de fécondation in vitro, nous avons cherché à mettre en évidence les caractéristiques permettant de prédire le caractère récidivant des échecs de fécondation. Pour cela, nous avons mené une étude rétrospective de 115 dossiers de couples engagés dans un programme de fécondation in vitro (FIV), sélectionnés sur une absence de transfert entre le $1 / 1 / 1992$ et le 31/12/1993. L'ensemble des tentatives de FIV réalisées par ces couples dans notre centre (288 cycles) a été revu. Pour juger du caractère récidivant ou non des échecs de fécondation lors d'une tentative de FIV classique, les dossiers comportant au moins 2 cycles de FIV ont été sélectionnés, en excluant les modalités particulières de FIV (FIV avec sperme de donneur, FIV avec spermatozoïdes épididymaires, FIV avec ICSI). Nous avons procédé à une étude comparant les caractéristiques des couples classés en 2 groupes: un groupe "non récidivant", n'ayant présenté qu'un seul échec de fécondation sur 2, 3 ou 4 FIV (35 couples; 97 FIV) et un groupe "récidivant", ayant présenté au moins 2 échecs de fécondation sur 2, 3 ou 4 FIV ( 21 couples; 52 FIV).

Les couples du groupe "récidivant" présentent, par rapport groupe "non récidivant":

- un facteur masculin dans l'indication de FIV plus fréquent $(71,4 \%$ vs $40 \% ; \mathrm{p}<0,05)$,

- un volume testiculaire (droit \pm gauche) plus bas $(33,7 \pm 6,2$ vs $39,3 \pm 9,2 \mathrm{ml}$; $\mathrm{p}<\mathrm{O}, \mathrm{OS})$,

- au spermogramme, un nombre moins important de spermatozoïdes mobiles en trajet direct, initialement $(50,5 \pm 53,5$ vs $91,0 \pm 81,3106 / \mathrm{ej} ; \mathrm{p}<0,05)$ et à 6 heures $(38,2 \pm 42,1$ vs $80,3 \pm 76,6$ 106/ej; $p<0,05)$, une leucospermie plus forte $(0,72 \pm 1,98$ vs $0,05 \pm 0,14 ; \mathbf{p}<0,05)$,

- après sélection sur gradient de Percoll, une diminution du pourcentage de spermatozoïdes mobiles $(47,6 \pm 25,3$ vs $67,2 \pm 21,6 \%$; $\mathrm{p}<0,05)$, de la vitesse curvilinéaire $(66,6 \pm 13,7$ vs $78,5 \pm 11,8 \mathrm{~mm} / \mathrm{s} ; \mathrm{p}<0,01)$, de la vitesse en trajet direct $(35,9 \pm 14,5$ vs $47,2 \pm 14,3 \mathrm{~mm} / \mathrm{s} ; \mathrm{p}<0,05$ ),

- un pourcentage plus élevé de test Penetrack anormal $(47,1 \%$ vs $13,6 \% ; p<0,05)$,

- sur le sperme utilisé pour la FIV sans fécondation, une diminution de la concentration des spermatozoïdes mobiles $(22,7 \pm 29,2$ vs $27,9 \pm 20,4106 / \mathrm{ml} ; \mathrm{p}<0,05)$ et une diminution de la numération des spermatozoïdes mobiles en trajet direct après sélection sur gradient de Percoll $(5,72 \pm 5,32$ vs $6,35 \pm 3,15106 / \mathrm{ml} ; \mathrm{p}<0,05$ ), enfin un pour- 
centage plus élevé de déficit de la fixation des spermatozoïdes sur la zone pellucide lors de la FIV: ( $75 \%$ vs $35,3 \%$; $p<0,001)$.

Dans le groupe "non récidivant", nous avons comparé les caractéristiques des FIV avec ou sans échec de fécondation; les FIV avec échec de fécondation se caractérisent par

- un nombre plus faible d'ovocytes recueillis $(7,8 \pm 5,3$ vs $9,7 \pm 6,1 ; p<0,05)$,

- un nombre plus faible d'ovocytes matures $(3,8 \pm 3,0$ vs $5,5 \pm 3,6 ; p<0,05)$,

- et enfin, un pourcentage plus élevé de déficit de la fixation des spermatozoïdes sur la zone pellucide $(35,3 \%$ vs $9,7 \% ; p<0,01)$.

Ainsi, les échecs isolés de fécondation paraissent liés à un faible nombre d'ovocytes matures recueillis, par contre, les échecs récidivants de fécondation semblent plus en rapport avec des altérations masculine.

FIV ET INFERTILITE MASCULINE: OPTIMISATION DU TAUX DE GROSSESSE APRES MODIFICATION DE LA TECHNIQUE DE CAPACITATION DU SPERME: ETUDE PROSPECTIVE SUR 79 CAS.

C. Wittemer, J. OHL, K. BetTAHAR-

Lebugle, L. Moreau, P. Delienbach

Département de P.M.A., service de gynécologie-obstétrique, C.M.C.O. 67300 Strasbourg-Schiltigheim

\section{Introduction}

La mise au point de l'ICSI est sans conteste une percée majeure dans le traitement de l'infertilité masculine. Cependant, la FIV classique demeurera dans de nombreux cas la technique de première intention voire la seule disponible. Dans cette optique, nous avons cherché à optimiser les techniques de capacitation classiques en combinant l'utilisation de produits connus de longue date: pentoxyfylline, 2 'deoxyadenosine et liquide folliculaire.

\section{Matériel et Méthodes}

Les techniques de stimulation- ovarienne, de recueil ovocytaire et de transfert embryonnaire sont celles utilisées classiquement dans notre centre.

Seule la technique de capacitation du sperme differe :

le sperme frais mélangé volume à volume avec du B2 $+10 \%$ sérum (de la conjointe) et $3 \mathrm{mM}$ de pentoxyfylline (PTF) est déposé sur un gradient de Percoll. Après lavage, le culot est repris dans du B2 avec $3 \mathrm{mM}$ 2 déoxyadénosine et incubé 45 minutes à $37^{\circ} \mathrm{C}$. Après lavage, le culot de spermatozoïdes est repris dans du B2 et utilise pour l'insémination des ovocytes. Spermatozoïdes et ovocytes sont incubés 18 heures dans du B2 contenant 50\% de liquide folliculaire de la femme. La suite des événements est identique à celle de toutes les autres tentatives de FIV.

\section{Résultats}

Cette étude a été menée au C.M.C.O. de janvier 1994 à juin 1995 et a concerné 79 couples repartis en deux groupes 1 et 2 .

- Le groupe 1: 49 couples ayant connu 1 ou 2 échecs de FIV antérieurs ( $<12 \%$ fécondation, aucune grossesse).

- Le groupe 2: 30 couples ayant un sperme de mauvaise qualité, susceptibles de bénéficier d'une ICSI et pour lesquels c'était la première tentative de PMA. 


$\begin{array}{lcc}\text { sté masculine pure } & 11 & 17 \\ \text { sté multifactorielle } & 27 & 13 \\ \text { sté +/- inexpliquée } & 11 & 0 \\ \text { \% fécondation } & 30 & 31,2 \\ \text { nombre TE } & 30 & 16 \\ \text { Grossesses } & 11 & 10 \\ \text { \% G/PO } & 22,5 & 30 \\ \text { \% G/TE } & 37 & 62,5\end{array}$

\section{Discussion}

Les taux de grossesse obtenus pour cette population de "mauvais cas" nous amènent à la question suivante: ne faudrait-il pas utiliser cette technique de capacitation dans tous les cas de FIV? D'autre part, les résultats obtenus dans le groupe 2 montrent l'intérêt qu'il peut y avoir à ne pas orienter directement les couples en ICSI. En particulier dans les centres de PMA ne disposant pas obligatoirement de la technique de microinjection!

Afin de préciser le rôle causal du facteur hormonal dans les dysfonctions érectiles (DE), et le bilan hormonal le plus approprié compte-tenu des nécessités d'économie en matière de santé, nous avons analysé les résultats des dosages hormonaux pratiqués chez les 852 derniers hommes ayant consulté notre centre pour DE.

\section{Matériels et Méthodes}

852 hommes consultant pour DE ont eu un dosage de testostérone (test.) plasmatique totale. 320 d'entre eux ont aussi eu un dosage de test. libre, 274 de test. non liée à la Sex Hormone Binding Globulin (SHBG) (test. biodisponible) et 334 un dosage de prolactine (PRL) à jeun et après $20 \mathrm{mn}$ de décubitus. La test. a été dosée par méthode radio-immunologique (RIA). La test. libre l'a été après purification et dialyse, et la test biodisponible après précipitation de la SHBG par le sulfate d'ammonium. La PRL a été dosée par RIA jusque 1993 puis par immunochimiluminescence.

La plupart des résultats anormaux ont été recontrôlés. Afin de déterminer la responsabilité des anomalies, les données hormonales ont été comparées aux données cliniques (antécédents, histoire de la $\mathrm{DE}$, intérêt sexuel = IS, examen clinique), aux résul- 
tats des autres explorations de l'impuissance, et à ceux des traitements hormonaux (androgènes, gonadotrophines chorioniques, bromocriptine $=\mathrm{BCR}$ ). Les résultats de cette série de dosages non systématiques de la PRL ont été comparés à ceux de dosages systématiques faits précédemment dans notre centre chez 1370 hommes.

\section{Résultats}

La test. totale était abaissée $(<3 \mathrm{ng} / \mathrm{ml})$ chez 59 hommes $(7.5 \%)$, et très abaissée $(<$ $2 \mathrm{ng} / \mathrm{ml})$ chez $13(1.5 \%)$. Parmi 35 valeurs abaissées recontrôlées dans le même laboratoire, le second dosage fut normal 15 fois $(43 \%)$. Parmi 39 hommes avec test. $<3$ $\mathrm{ng} / \mathrm{ml}$, et dont il fut possible de juger objectivement de la responsabilité du facteur hormonal, celui-ci ne paraissait en cause que 9 fois ( $23 \%$ ) dont $7(18 \%)$ de façon prédominante, et 2 (5\%) de façon partielle. La test. totale était aussi souvent abaissée en cas d'IS normal ( $7 \%$ ) que d'IS diminué (8.2 $\%)$. Ne la doser qu'en cas d'IS diminué ou d'anomalie clinique aurait conduit à méconnaître $44 \%$ des cas avec test. $<3 \mathrm{ng} / \mathrm{ml}$ et $33 \%$ de ceux qui furent clairement améliorés par les androgènes.

Le dosage de test. libre ne s'avéra utile dans aucun cas. Parmi 28 patients avec test. totale $<3 \mathrm{ng} / \mathrm{ml}$, il n'était pas plus souvent abaissé chez ceux avec responsabilité prouvée du facteur hormonal $(75 \%)$. Parmi 27 cas avec test. libre électivement abaissée, les androgènes ne furent efficaces, et seulement discrètement, que chez $25 \%$.

La test. biodisponible fut un peu plus informative. Parmi 21 patients avec test. totale normale, elle était abaissée $(<0.85 \mathrm{ng} / \mathrm{ml})$ chez 4 des 6 cas avec responsabilité du facteur hormonal contre 8 des 15 cas sans responsabilité. Parmi 15 cas avec abaissement électif, la contribution hormonale était prépondérante une fois et probable, mais partielle, 4 fois. En définitive, ce dosage n'eut qu'une seule fois des conséquences importantes.
Chez 334 patients sélectionnés sur la base d'une diminution de l'IS, d'une gynécomastie, ou d'une test. totale $<4 \mathrm{ng} / \mathrm{ml}$, la PRL ne fut trouvée élevée que deux fois (30 et 40 $\mathrm{ng} / \mathrm{ml}$ ). Seul le second cas fut amélioré sexuellement par la BRC. Aucun n'avait de tumeur hypophysaire. Ces données ont confirmé la diminution progressive de l'incidence des hyperprolactinémies constatée dans notre centre depuis 1978: parmi 539 patients ayant bénéficié d'un dosage systématique entre 1978 et $1982,2.2 \%$ avaient une PRL entre 20 et $35 \mathrm{ng} / \mathrm{ml}, 1 \%>35$ $\mathrm{ng} / \mathrm{ml}$, révélant 4 fois sur $5(0.76 \%)$ une tumeur hypophysaire. Après avoir étudié 1704 patients, dont 1370 avec dosage systématique, les incidences correspondantes ne sont plus que de $1.63 \%, 0.65 \%$ et $0.35 \%$. La BRC n'améliora que $40 \%$ des patients avec PRL entre 20 et $35 \mathrm{ng} / \mathrm{ml}$, ce qui est peu différent de l'effet placebo, mais $64 \%$ (7 sur 11) des cas $>35 \mathrm{ng} / \mathrm{ml}$.

\section{Commentaires et Conclusions}

Nos données, intégrées à une méta-analyse des grandes séries de la littérature, confirment la très faible prévalence du facteur hormonal dans les DE: diminution de la test. totale dans $8.5 \%$ des cas, augmentation significative de la PRL ( > 35 ng/ml) dans 0.7 $\%$. La diminution avec le temps de l'incidence des hyperprolactinémies et des tumeurs hypophysaires s'explique probablement par le fait qu'on a découvert, dans les premières années qui ont suivi la diffusion du dosage de la PRL, un grand nombre de cas anciens, non diagnostiquables jusque là. La détection systématique de ces anomalies hormonales ne débouche sur un traitement efficace qu'au plus dans $27 \%$ des DE non sélectionnées. Les seules autres conséquences significatives du bilan hormonal sont la détection de tumeurs hypophysaires dans $0.3 \%$ des cas (compilation de 4246 patients). Trois séries totalisant 1077 cas avec dosage systématique de la test. n'ont pas conduit à découvrir une seule autre pathologie qu'il eut été préjudiciable de méconnaître. 
Ces données ne justifient pas un bilan hormonal systématique en cas de DE. Il faut se baser sur l'âge, l'examen clinique et l'IS. Avant 40 ans, si clinique et IS sont normaux, aucun dosage n'est nécessaire. Après 40 ans, ou en cas d'anomalie clinique, la test. totale suffit. En cas de gynécomastie ou de test. $<4 \mathrm{ng} / \mathrm{ml}$, il faut ajouter la PRL, et en cas d'IS diminue, la PRL et éventuellement TSH. Tout dosage anormal doit être vérifié. Test. libre et biodisponible, comme FSH et LH, ne sont pas justifiées en routine.

\section{EVALUATION DU CONTEXTE HOR- MONAL CHEZ DES PATIENTS PRE- SENTANT DES TROUBLES RESPIRA- TOIRES DURANT LE SOMMEIL (HYPOPNEES OU SYNDROME DES APNEES DU SOMMEIL (SAS)}

\author{
A. LEMAIRE, J.BUVAT \\ Association EPARP 47.49 rue de la Bassée \\ LILLE 59000
}

Nous avons déjà rapporté, comme d'autres auteurs, l'importante fréquence des apnées ou des hypopnées survenant durant le sommeil chez des sujets présentant des troubles érectiles avec anomalies de l'enregistrement des érections nocturnes .

Nous évaluons dans cette étude le contexte hormonal de ces patients ainsi que le retentissement sur la libido et l'éventuelle relation à la pathologie respiratoire .

\section{Matériel et Méthodes}

Les paramètres cardiorespiratoires ont été étudiés avec le système informatisé IMS 200 - CARDAS. Ils furent recueillis au moyen de divers capteurs: détecteur infrarouge d'oxymétrie;détecteur de mouvements fixe au poignet;capteurs thoracique et abdominal;microphone trachéal;matelas détecteur de mouvements. Nous avons retenu les paramètres suivants:

- saturation minimum en 02 (SaO2)

- nombre et durée des apnées

Les modifications du rythme cardiaque et respiratoire ainsi que $d u$ tonus musculaire ont permis de définir indirectement la qualité du sommeil des patients explorés.

L'enregistrement des érections nocturnes a été effectué au moyen du rigiscan. Le tracé était jugé normal lorsqu'il était mis en évidence au moins deux érections d'une durée supérieure à 10 minutes et d'une rigidité d'au moins 70\% (selon le rigiscan). Dans le cas contraire, le tracé était considéré pathologique.

L'enregistrement s'est effectué pour tous les patients dans les mêmes conditions de température ambiante. Il se déroulait de 22 heures à 7 heures .

Après la nuit d'enregistrement, le prélèvement sanguin était effectué ;les paramètres hormonaux suivants étaient dosés: testostérone totale, libre, biodisponible, LH, FSH.

38 patients, âgés de 37 à 65 ans, ont été explorés.

\section{Résultats}

Les patients furent répartis en 2 groupes selon que la rigidimétrie nocturne était normale (groupe $1 ; n=18$ ) ou pas (groupe $2 ; n=20$ ).

Parmi les patients présentant une PEN normale ( groupe I), la $\mathrm{SaO} 2$ minimum était toujours supérieure à $90 \%$ à l'exception d'un cas. La $\mathrm{SaO} 2$ minimum moyenne était égale à $90.5 \% \pm 2.27$. En revanche, parmi les patients ayant une PEN présentant des anomalies (groupe 2), on retrouvait chez 15 patients une $\mathrm{SaO} 2$ inférieure à $90 \%$. La testostérone totale ainsi que ses fractions actives, à savoir la testostérone libre et biodisponible, étaient légèrement plus basses dans le groupe 2 que dans le groupe 1. 


\begin{tabular}{|c|c|c|c|}
\hline patients & $\begin{array}{l}\text { testosté } \\
\text { rone totale }\end{array}$ & $\begin{array}{l}\text { testostérone } \\
\text { libre }\end{array}$ & $\begin{array}{c}\text { testost. } \\
\text { biodisponible }\end{array}$ \\
\hline Groupe & 16.94 & 22.19 & 1.85 \\
\hline Groupe & 25.38 & 18.66 & 1.55 \\
\hline
\end{tabular}

La différence n'est pas significative .En outre, nous avons mis en évidence une relation entre la saturation minimale en 02 et le taux de testostérone biodisponible, comme cela a déjà été rapporté par d'autres auteurs ( $\mathrm{r}=0.428390 ; \mathrm{p}<.01$ )

La libido a été évaluée selon les données de l'interrogatoire parmi 15 patients du groupe I et 13 patients du groupe 2 Elle était jugée diminuée 3 fois sur 13 parmi les patients du groupe 2 alors que le taux de testostérone restait supérieur à $3 \mathrm{ng} / \mathrm{ml}$.

\section{Conclusion}

Nos données confirment l'association fréquente des taux abaissés de testostérone aux hypopnées et aux apnées du sommeil . Différents auteurs ont confirmé l'existence d'un hypogonadisme dans le cadre des SAS. Celuici pourrait être central, l'hypoxie favorisant l'augmentation des opioïdes endogènes, qui ont un rôle inhibiteur sur la libération des gonadotrophines. Il pourrait aussi être périphérique par une atteinte directe des cellules de Leydig secondaire à l'hypoxie.

\section{RESULTATS A 2 ANS D'UNE ETUDE MULTICENTRIQUE EUROPEENNE SUR LA SECURITE ET L'EFFICACITE DU TRAITEMENT PAR AUTO-INJEC- TIONS INTRACAVERNEUSES DE PROSTAGLANDINE El (PGEl) CHEZ DES PATIENTS AVEC DYSFONCTION ERECTILE CHRONIQUE.}

\author{
J. Buvat*, D. Hauri, G.S. Krotovshy, E. \\ Meuleman, V. Michal, H. Porst, G. WaG- \\ NER, E. WESPES
}

\footnotetext{
* Association pour l'etude de la pathologie de l'appareil reproducteur et de la psychosomatique (EPARP), 49 rue de la Bassee - 59000 LILLE
}

Nous rapportons ici les résultats à 2 ans du premier essai prospectif d'injection intracaverneuse de substance vaso-active réalisé selon les règles des bonnes pratiques cliniques. Cet essai débuta en 1991 dans 8 centres européens.

\section{Matériels et Méthodes}

Cent soixante deux patients (âge moyen 54 ans) avec dysfonction érectile d'étiologie diverse, évoluant depuis au moins 6 mois, ont été inclus. Tous répondaient à des doses de 1 à $20 \mu \mathrm{g}$ de PGEl (ALPROSTADILALPHADEX, Laboratoires Schwarz Pharma). Les patients psychogènes n'étaient inclus qu'après échec d'un traitement psychothérapique ou sexothérapique. Après recherche de la dose minima efficace et apprentissage de la méthode des auto-injections, les patients ont été revus tous les 2 mois. Ils ont bénéficié de bilans biologiques systématiques tous les 2 mois pendant la première année, puis tous les 6 mois, d'examens cliniques complets et d'électrocardiogrammes tous les 6 mois, d'un pharmacodoppler pulse tous les ans. Les résultats du traitement, et les effets indésirables, furent évalués lors de chaque consultation. Cellesci comportaient particulièrement la recherche systématique d'anomalies locales et particulièrement de zones de fibrose. Les patients devaient consigner les résultats des injections sur des agendas spéciaux, et remplissaient également chaque année, comme leur partenaire, un questionnaire évaluant leur degré de satisfaction du traitement, et l'impact de celui-ci sur leur vie psychologique et conjugale.

\section{Résultats}

Cent seize des 162 patients ont poursuivi le traitement jusque la fin de la première année. Parmi ceux-ci, 80 (âge moyen 51 ans) ont débuté la seconde année de traite- 
ment, et 74 l'ont finie. Parmi les 46 patients qui ont arrêté le traitement pendant la première année, 7 l'ont fait pour effets indésirables incluant l'apparition de nodules aux sites d'injection, des érections douloureuses, des érections prolongées, et dans un cas une suspicion de réaction allergique. Les 116 patients qui complétèrent la première année firent 6400 injections dont $91 \%$ furent suivies de rapport. Les 74 qui complétèrent la seconde firent 3860 injections dont $94 \%$ furent suivies de rapport. Cette amélioration avec le temps du taux de succès des injections intracaverneuses se retrouva dans chaque groupe étiologique, et même en ne prenant en compte que les sujets ayant poursuivi le traitement pendant les 24 mois. Quatre-vingt neuf pour cent des patients rapportèrent une amélioration de leur personnalité, et $80 \%$ une amélioration de leur relation de couple, sous l'effet des injections.

En ce qui concerne les effets indésirables, pendant la première année 14 patients $(8.6 \%)$ présentèrent des érections de plus de 3 heures, et 2 patients un total de 5 érections de plus de 6 heures. Il ne fut plus observé de priapisme au cours de la seconde année, et seulement 5 patients $(6.2 \%)$ présentèrent un total de 15 érections de plus de 3 heures. Durant les deux, 13 patients $(7.9 \%$, dont 11 dés la première année, et 2 la seconde année), installèrent des modifications fibreuses telles que nodules souscutanés, plaques ou nodules des corps caverneux $(n=10)$, induration plus diffuse des corps caverneux $(n=2)$, ou courbure $d u$ penis $(n=1)$. Dix d'entre eux avaient eu des hématomes ou fait des injections sous-cutanées, ou des injections inefficaces, avant l'apparition de ces nodules, évoquant la responsabilité d'une technique d'injection défectueuse. Vingt cinq pour cent des patients ont décrit une douleur suite aux injections. Dans la majorité des cas, il s'agissait d'une minime sensation de tension. La douleur n'a gêné le rapport que chez 7 sujets la première année $(4.3 \%)$ et 2 la seconde année $(2.5 \%)$. Seuls 2 patients ont arrêté le traitement du fait de cet effet indésirable.

\section{Conclusion}

Les deux premières années de cet essai à long terme, qui se poursuit actuellement, montrent donc que les auto-injections de PROSTAGLANDINE El (PGE1) sont un traitement efficace, assez bien toléré, et sans danger important, des dysfonctions érectiles chroniques.

\section{CHIRURGIE PENIENNE D'AGRAN- DISSEMENT : TRAITEMENT CHIRUR- GICAL OU “ PENIS BUILDING "? TECHNIQUE ? INDICATIONS ? LIMITES ? CONTRE-INDICATIONS.}

$$
\begin{gathered}
\text { M.SCHOUMAN*, M.ABECASSIS**, } \\
\text { J.MIGNOT*** }
\end{gathered}
$$

Centre d'Urologie, d'Andrologie et de Sexologie164, avenue Charles de Gaulle-92200 NEUILLY.

*Uro-Andrologie, **Médecine esthétique, ***Psycho-sexologue.

La chirurgie pénienne d'agrandissement a recours à des techniques permettant d'agir sur la longueur de la verge d'une part, et d'autre part sur la circonférence.

\section{Metériel et Méthodes}

Parmi les différentes techniques proposées notre choix s'est fixé sur :

- la section du ligament suspenseur associée à une plastie cutanée pour l'allongement,

- la ponction réinjection de graisse traitée dans l'espace péricaverneux pour l'épaississement (Lipo-péno-sculpture).

L'allongement prévisible est de $2 \mathrm{~cm}$ en moyenne et concerne la taille de la verge au repos comme en érection. Une plastie pénoscortale est parfois nécessaire pour compléter la tubulisation de la racine de la verge. 
L'épaississement est calculé en fonction des mensurations du patient, de la quantité de graisse prélevable (c'est exceptionnellement un facteur limitant) et de la résorption prévisible d'environ $45 \%$ qui conduit à surdoser la quantité de graisse réinjectée. Une résorption trop importante conduit à une ré-injection . Le prélèvement et la réinjection de la graisse peuvent être réalisés en ambulatoire. L'allongement nécessite pour sa part une anesthésie et une courte hospitalisation.

Une population de 307 patients ont été traités, 11 par ligamentoplastie seule, 27 par intervention mixte, 269 par lipo-péno-sculpture seule.

\section{Résultats}

La ligamentoplastie permet en moyenne un allongement de $2 \mathrm{~cm}$ que l'on conserve grâce à l'adjonction de la plastie cutanée (conformément aux travaux de Bondil et Delmas sur le cadavre). La section ligamentaire étant subtotale, on n'a jamais observé de modification de la qualité des érections de l'angle péno-abdominal.

La lipo-péno-sculpture permet un gain moyen de $1,8 \mathrm{~cm}$ en épaisseur. Compte tenu de la résorption, le résultat est stable après 6 mois. L'indice de satisfaction après la première injection est de $70 \%$. Une seconde injection peut-être pratiquée sous anesthésie locale. Des interventions secondaires, de type circoncision par exemple, ont permis de constater qu'il s'agissait de véritables greffes de graisse avec constitution d'un tissu graisseux organisé (confirmation anatomo-pathologique).
Les complications observées sont de type infectieux, observées sur 4 cas rapprochés dans le temps. Elles étaient dues à un défaut de stérilisation du matériel et ont eu comme conséquence un retard de cicatrisation.

\section{Indications}

\section{3 populations se dégagent :}

- Les petites verges "vraies ". Indication indiscutable avec prise en charge par l'assurance maladie.

- Les indications purement esthétique (verge normale mais souhaite plus - à rapprocher de la chirurgie mammaire). Conseil psychologique. Pas de prise en charge par la Sécurité Sociale.

- Les dysmorphophobiques : Evaluation psychologique obligatoire. Attention aux délires localisés ou paranoïaques. Ces patients ne seront jamais satisfaits et peuvent aller jusqu'à la violence verbale, voire physique. La frontière avec la population précédente est difficile à établir, d'où l'importance du travail en équipe avec les psycho-sexologues.

\section{Conclusion}

L'augmentation de volume de la verge est une intervention techniquement réalisable sans difficultés ni conséquences facheuses sur le plan anatomique. La sélection rigoureuse des patients est une étape capitale et doit faire appel à une équipe pluridisciplinaire. 


\section{DIVERS}

\section{APPORT DE L' EXPLORATION BIO- LOGIQUE, CLINIQUE ET RADIOLO- GIQUE AUX O.A.T.S ASSOCIEES A UNE INFECTION SPERMATIQUE ET/OU UNE LEUCOSPERMIE}

\author{
N. Rives1, L. Sibert2, B. Mace1 \\ 1. Laboratoire de biologie de la reproduction, \\ CHRU Charles Nicolle, 76031 Rouen \\ 2. Service d'Urologie, CHRU Charles Nicolle, \\ 76031 Rouen
}

\section{Introduction}

Un spermogramme effectué chez des hommes infertiles révèle dans près de $80 \%$ des cas une oligoasthénospermie (OATS). Les causes les plus fréquemment retrouvées sont la varicocèle, les infections spermatiques, la cryptorchidie, I'existence d'anticorps antispermatozoïdes et les anomalies structurales du spermatozoïde.

Le but de ce travail est de mettre en évidence l'intérêt d'effectuer une exploration biologique, clinique et radiologique dans les OATS associées à une infection du plasma séminal et/ou une leucospermie.

\section{Sujets et Méthodes}

22 hommes consultant par une infécondité et présentant une OATS associée à une infection du plasma séminal (spermoculture positive, présence de chlamydiae (chlamydiae trachomatis). mycoplasmes (Ureaplasma urealyticum), ( $n=15)$, ou à une leucospermie isolée $(\mathrm{n}=7)$ ont bénéficié:

- d'un dosage du fructose, de la L-carnitine, du zinc et de la transferrine dans le liquide séminal.
- d'un examen cytobactériologique urinaire (ECB) selon la technique de Stamey.

- d'un examen clinique urologique

- d'une échographie scrotale et prostatique par voie transrectale

\section{Résultats}

$74 \%$ des patients présentent une baisse d'au moins un marqueur séminal, le plus souvent évoquant une atteinte prostatique. L'ECB des urines est positif dans $60 \%$ des cas. Le germe est essentiellement retrouvé dans l'urine du ler jet et après massage prostatique. Il correspond au germe retrouvé dans le plasma séminal dans $46 \%$ des cas.

$70 \%$ des patients ont un signe clinique urologique ou signe échographique, la varicocèle et les signes d'atteinte prostatique (hypertrophie prostatique, sensibilité prostatique et calcifications intraprostatiques) étant les plus fréquents. L'échographie confirme l'examen clinique dans $60 \%$ des cas (varicocèle et signes prostatiques). $66 \%$ des ECB positifs du liquide séminal présentant une baisse des marqueurs séminaux prostatiques sont associés à une anomalie clinique et échographie.

\section{Conclusion}

Une exploration complète biologique, clinique et radiologique des OATS permet un diagnostic étiologique dans $70 \%$ des cas pouvant conduire à une attitude thérapeutique éventuelle (cure d'une varicocèle, par exemple) ou une attitude préventive (antibiothérapie prophylactique pour les OATS dans un contexte d'infection urinaire et de prostatite chronique) avant de débuter un programme de procréation médicalement assistée. 
HYPOSPERMIE, KYSTE PROSTATIQUE ET INFERTILITE A PROPOS DE 4 CAS

JM. Rigot*. B. HATTAB*, L. LEMAITRE**, E. MAZFMAN*

${ }^{*}$ Clinique urologique Professeur E. Mazeman CHRU LILLE ${ }^{* *}$ Clinique Radiologique Professeur L. Lemaitre CHRU LILLE

La prise en charge d'une infertilité masculine due a une obstruction de l'appareil génital profond est difficile. A la classique résection des canaux éjaculateurs les auteurs proposent dans un premier temps une ponction évacuatrice sous contrôle échographique avec analyse du contenu kystique, éventuellement congélation du sperme et opacification du kyste. En cas d'échec ou de récidive du kyste ils réalisent une marsupialisation endoscopique sous contrôle échographique.

\section{Résultats}

Patient $\quad \mathrm{v} / \mathrm{n} / \mathrm{m} \quad \mathbf{p} \quad \mathrm{v} / \mathrm{m} / \mathbf{n} \quad$ m.s.e $\quad \mathrm{v} / \mathrm{n} / \mathrm{m} \quad$ g 132 ans $40,1 / 0 / 0+0,1 / 7 / 50+4,8 / /$. . 239 ans $61,5 / 21 / 0+1,2 / 40 / 10+1,2 / 40 / 10$. 333 ans 5 0,8/10/10 - 12,5/65/20 + 3,5/13/15 + 424 ans $21,2 / 4 / 0+3,1 / 44 / 55$ - - +

PATIENTS n ${ }^{\circ}$ - âge - durée d'infertilité en ans

V/N/M: Volume/ml - Numération 10 6/ml. Mobilite \% à la première heure.

$G$ : grossesse

$\boldsymbol{P}$ : ponction du kyste sous échographie, présence de spermatozoïdes mobiles.

M.SE.: marsupialisation sous contrôle échographique

\section{Discussion}

L'intérêt de la ponction précédant la chirugie endoscopique est double:

- Diagnostic précis des lésions c'est à dire kyste séminal inférieur au kyste prostatique;
- Prélèvement riche en spermatozoïdes mobiles (3/4) et la congélation possible (3/3) permettent d'envisager ultérieurement une aide médicale à la procréation en cas d'échec de la marsupialisation sous contrôle échographique. En effet si la marsupialisation sous contrôle échographique préserve au maximum la dynamique de l'urèthre prostatique on constate une amélioration du volume seulement $2 / 3$ et la survenue de grossesse $2 / 4$.

\section{AGENESIES VESICULO-DEFEREN- TIELLES ET GENE C.F.T.R.}

\author{
F.Pigeon *, D.Gaillard **, C. Clavel **, \\ C.FEREC *****, B.DELEPINE *, MC. MELIN*, \\ G.HARIKA ***, Y.YOUINOU ****, P.VILLENA \\ ****, B.LARDENNOIS ****, C.QUEREUX *** \\ * Laboratoire de cytogénétique et Biologie de la \\ Reproduction. ${ }^{* *}$ Laboratoire Pol Bouin. ***Ser- \\ vice de Gynécologie-Obstétrique. *****Service \\ d'Urologie. -C.H.U. REIMS - ${ }^{* * * * *}$ Centre de Bio- \\ génétique-CTS de BREST.
}

Environ $60 \%$ des hommes présentant une agénésie vésiculo-déférentielle bilatérale (CBAVD) isolée sont porteurs d'au moins une mutation du gène C.F.T.R.(Cystic Fibrosis Transmembrane Conductance Regulator)[1,2]. La corrélation avec la mucoviscidose avait déjà été démontrée en 1968 par Kaplan et col.[3].

\section{Anomalie constitutionnelle ou acquise?}

Un examen morphologique de l'appareil génital a pu être réalisé chez un foetus masculin porteur de la délétion DF508 à l'état homozygote. Le développement des épididymes, canaux déférents et vésicules séminales est normal à 14 semaines d'aménorrhée. L'agénésie décrite chez l'enfant et 
l'adulte [4] est donc un processus secondaire (obstruction ou ischémie) ou l'expression $\mathrm{du}$ gène C.F.T.R. est vraisemblablement en cause [5].

Étude de 16 patients présentant une CBAVD :

Nous avons pu réaliser une étude en Biologie Moléculaire, couplée à une exploration urologique et spermiologique chez 13 patients porteurs d'une CBAVD isolée et 3 atteints de mucoviscidose (forme respiratoire). 13 exons ont été analysés par D.G.G.E. actuellement.

-pour les 13 CBAVD isolées :

- 4 sont hétérozygotes composites

- 5 sont hétérozygotes pour la DF508

- 4 sont négatifs

soit $69 \%$ de patients présentant au moins une des mutations analysées et $30,7 \%$ d'hétérozygotes composites.

-les 3 patients atteints de mucoviscidose sont pour l'un homozygote DF508 et hétérozygotes composites pour les 2 autres.

Ces patients porteurs de CBAVD peuvent à l'heure actuelle bénéficier d'lCSI après prélèvement de spermatozoïdes épididymaires. La recherche d'hétérozygotie chez la femme est un préalable indispensable mais le conseil génétique restera délicat, en cas de transmission foetale, devant l'absence de corrélation génotype-phénotype.

\section{REFERENCE}

1 DUMUR V., GERVAIS R., RIGOT J.M.et al., Lancet,1990,336,512.

2 PATRIZIO P., ASCH R.,HANDELIN B.et al., Hum. Reprod., 1993,8.215-220.

3 KAPLAN E., SHWACHMAN H.,PERLMUTTER A.D.et al.,N. Engl. J. Med.,1968,279,6569.

4 VALMAN H.B., FRANCE N.E.et al. Lancet,1969,566-567.

5 MICKLE J.,MILUNSKY A.,AMOS I.A.et al.,Hum. Reprod.,1995,10,1728-1735. 